\title{
Investigation of Power losses on Solar Photovoltaic Array Interconnections Under Mismatch Conditions
}

\author{
Sai Krishna $\mathrm{G}^{1}$ (D) . Tukaram Moger ${ }^{1}$
}

Received: 19 February 2021 / Accepted: 13 September 2021 / Published online: 14 October 2021

(C) The Author(s), under exclusive licence to Springer Nature Singapore Pte Ltd. 2021

\begin{abstract}
The mismatch effect creates a difference between the sum of maximum power generated by individual Photovoltaic (PV) modules and the overall PV array power output. Mismatch effects can be classified into internal and external mismatch effects. Internal mismatch effect occurs because of factors such as manufacturing defects and ageing. The external effect occurs because of variations in solar irradiance and temperature. This paper presents the investigation of internal and external mismatch effects on various $5 \times 4$ Photovoltaic $(\mathrm{PV})$ array interconnections such as series-parallel, total-cross-tied, bridgelink, honey-comb, hybrid SP-TCT, hybrid BL-TCT, along with proposed hybrid HC-TCT and hybrid HC-BL. Six mismatch case studies are considered in this paper to investigate the performance of PV array connections. Among the six cases, three cases are due to internal mismatch effects, and the remaining three cases belong to the external effects. In addition, the global maximum power point (GMPP), the voltage at GMPP, thermal voltage, power loss, fill-factor, efficiency $(\eta)$, and possible local peaks (PLP) parameters are calculated and compared for each PV array connection under all case studies using Matlab-Simulink. Also, for each PV array connection, the revenue generation is calculated from energy savings under mismatch effects. The paper summary shows that TCT, HC-TCT, and HC-BL array connections delivered beneficial results under external effects, and TCT, HC, HC-TCT, and HC-BL provided superior results under internal effects.
\end{abstract}

Keywords PV array modelling · Partial shadings · Global power output · PV array connections · PV efficiency

\section{Notations}

$G \quad$ : Actual irradiance of PV module

$I_{d} \quad$ : Diode current

$I_{s h} \quad$ : Shunt current of a PV cell

$I_{c e l l} / I_{p v}:$ PV cell/ module current (A)

$a \quad$ : Ideality factor

$n_{s} \quad:$ PV cells connected in series

$N_{S} \quad$ : Series connected PV modules

$N_{P} \quad$ : Parallel connected PV modules

$P_{M P P} \quad$ : Maximum power at uniform condition

$q \quad$ : Electron charge $1.6 \times 10^{-19} \mathrm{C}$

$R_{S} \quad:$ Series resistance of a PV module

$R_{P} \quad$ : Shunt resistance of a PV module

$T_{c} \quad$ : Operating temperature of a PV cell

$V_{c e l l} / V_{p v}: \mathrm{PV}$ cell/ module voltage (V)

Sai Krishna G

saikrishna240@gmail.com

1 Department of Electrical \& Electronics Engineering, National Institute of Technology, Karnataka 575025, India
$\begin{array}{ll}V_{d} & : \text { Voltage across the diode } \\ V_{T H} & : \text { Thermal voltage } \\ \eta & : \text { Efficiency }\end{array}$

Introduction

Nowadays, PV technology is advancing rapidly, with module efficiency increasing and manufacturing cost decreasing. These facts show that PV technology is approaching maturity [1, 2]. However, even with today's more advanced manufacturing techniques, the mismatch between identical design solar cells appears to be a minor flaw that cannot readily overcome. The differences in the electrical characteristics of solar cells result in mismatch failures within the PV module. Modules with distinct electrical characteristics result in a mismatch in the entire PV plant. According to the literature, the mismatch effects classified into internal and external mismatch effects [3, 4].

Internal mismatch effects are caused because of nonidentical properties of solar cells, such as series resistance $\left(R_{S}\right)$, shunt resistance $\left(R_{p}\right)$, ideality factor $(a)$, light generated current $\left(I_{L}\right)$, and diode saturation current $\left(I_{o}\right)$. 
According to the literature [5], the probability of $R_{S}$, $R_{s h}$ and $a$ parameters mismatch is high at the time of manufacturing. External mismatch effect occurs because of unequal solar irradiance and temperature of the PV module. Unequal solar irradiance is called the partial shading condition (PSC). Partial shading happens when telephone towers and passing clouds cover some part of the PV array. In PSCs, the shaded part receives less solar irradiance than the unshaded part [6]. This results in the hot-spot effect in a PV module, which damages the PV cell or module. An approach to protect the shaded PV modules from harm is by connecting bypass diodes across the terminals. The incorporation of diodes results in multiple peaks in the $\mathrm{P}-\mathrm{V}$ characteristics. Among multiple peaks, one global peak, which generates the highest maximum power, is recognized as a global maximum power point (GMPP). Because of numerous peaks, the MPPT can skip the GMPP. This results in an additional power loss in the $\mathrm{PV}$ system, and a reduction technique is required to mitigate these losses. According to the literature, many solutions have been reported to reduce losses resulting from PSCs. The most prevalent solution is the PV array interconnection $[7,8]$.

\section{Literature Survey}

Various types of PV array connections have been reported in the literature to reduce mismatch losses caused by partial shading, such as "simple-series (SS), parallel (P), seriesparallel (SP), total-cross-tied (TCT), bridge-link (BL), and honey-comb (HC)" [9]. In [10], the authors considered SP, TCT and BL PV arrays for reliability evaluation using the probabilistic approach under mismatch issues due to manufacturing tolerance. This paper indicates that the interconnection between PV modules (i.e., TCT and BL) can increase the operational lifetime by $30 \%$ as compared to SP PV array. The authors also examine the performance of array interconnections under partial shading and ageing conditions by obtaining the maximum power, fill-factor (FF) and power loss (PL) [11, 12]. The results conclusively established that TCT array shows superior performance as compared to $\mathrm{SP}$ and $\mathrm{BL} \mathrm{PV}$ arrays. In [9], developed a numerical model based on Newton-Raphson method for plotting the I-V and P$\mathrm{V}$ characteristics for different PV array interconnections such as; "SS, SP, TCT, BL and HC". In this study, the authors observed that TCT array produced the highest maximum power as compared to the other interconnections. In [13], investigated the performance of $5 \times 4$ "SS, P, SP, TCT, BL and HC" PV array interconnections under various PSCs. The results indicated that the TCT PV array exhibited the best performance in most cases of partial shadings. In [14], developed an optimum TCT PV array by assuming that this problem as a mixed integer nonlinear programming problem could be solved using the branch and bound (BB) algorithm to reduce irradiance mismatch index (IMI). In this approach, the location of shaded PV modules shifted from one row into other rows to increase global maximum power. Subsequently, the same authors proposed an optimal reconfiguration approach for TCT PV array to mitigate the PSCs [15]. In this approach, the shaded PV modules are shifted from one column to another using electrical switches to distribute the PSCs. In [16], authors proposed SuDoKu and Optimal SuDoKu PV array arrangements for TCT PV array to reduce mismatch losses and increase global maximum power under PSCs. In this study, the physical location of PV modules are rearranged based on the proposed methods to distribute the shading effects over the array. In [17], developed a novel $5 \times 5 \mathrm{PV}$ array interconnection and compared the performances of existing interconnections under PSCs. The performance of each connection is obtained by considering various parameters. The result shows that the proposed interconnection enhanced the global maximum power as compared to the existing PV arrays. In [18], authors investigated the performance of $5 \times 4$ "SS, P, SP, TCT and BL" PV arrays interconnection under partial shading and faulty conditions. In this study, the authors adopted seven indicators to assess the performance of each connection using MATLAB-SIMULINK model. The results showed that TCT and BL interconnections enhanced the global maximum power and fill-factor as compared to other connections. In [8], authors conducted a comparative study on $6 \times 6 \mathrm{PV}$ array by interconnecting the PV modules in various fashions like "SS, SP, TCT, BL, and HC" under different shading patterns. In this study, the authors assumed row, column and diagonal shading patterns for appraising the performance of each PV array. The results revealed that the TCT PV array overcomes the mismatch loss under most shading patterns. A similar approach is presented in [19]. In this paper, the authors incorporated a parallel interconnection with other array interconnections to assess the performance on a $5 \times 5 \mathrm{PV}$ array. The results indicated that TCT PV array provided better results than other PV array interconnections under PSCs. The same authors investigated the effect of mismatch losses on SS, SP, and HC PV array interconnections [20]. The results proved that the PV array mismatch loss is directly proportional to the number of modules connected in series. The HC interconnection has less number of series connections; therefore, the mismatch loss is limited compared to SS and SP. In addition to existing connections, the hybrid PV array connections such as hybrid SP-TCT and BL-TCT are introduced to address PS problem [21]. 


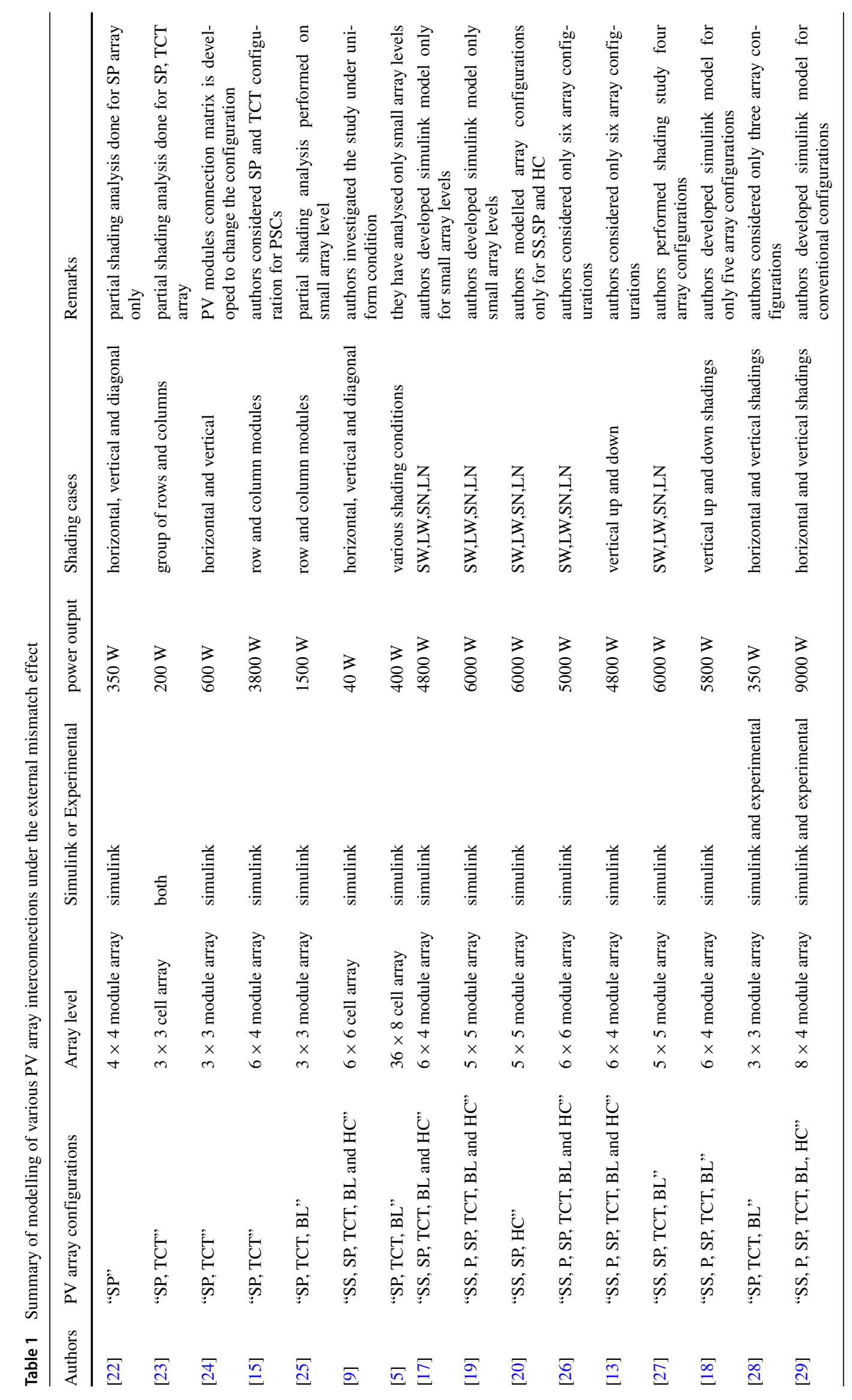


According to literature, the influence of external mismatch effects on conventional (i.e., SP, TCT, BL, HC) and hybrid PV arrays (i.e., SP-TCT, BL-TCT ) is addressed in multiple papers, which are reported in Table 1. Additionally, it is identified that, the effect of PSCs is investigated on smaller PV array sizes, such as $3 \times 3,4 \times 3,4 \times 4$, and $5 \times 4$ using Simulink platform. However, according to the authors understanding, the modelling and assessment of conventional and hybrid interconnections under internal mismatch effects have not yet been explored in literature. Therefore, this paper presents the impact of internal and external mismatch losses on the conventional and hybrid $\mathrm{PV}$ array interconnections such as "SP, TCT, BL, HC, and SP-TCT, BL-TCT", respectively. In addition to this, two new hybrid PV array interconnections, i.e., HC-TCT and HC-BL are proposed to investigate the mismatch loss along with other interconnections. Six case studies are considered to review the performance on $5 \times 4 \mathrm{PV}$ array. In six cases, three of them are due to an internal mismatch effect, and the remaining three belongs to the external mismatch effect. Besides, the global maximum power point (GMPP), voltage at GMPP $\left(V_{G M P P}\right)$, thermal voltage $\left(V_{T H}\right)$, power loss (PL), fill-factor (FF), efficiency $(\eta)$ and possible local peaks (PLP) parameters are obtained and compared for each array interconnection under all case studies.
Figure 1 describes the entire structure of this paper, including PV array connections, case studies, and parameters for the investigation. The rest of the paper is organized as follows; Section "PV array Interconnections" describes the various PV array interconnections reported in the literature. The detailed mathematical modelling of a PV array is presented in "Modelling of Photovoltaic Array". Section "Description of Case Studies" illustrates a detailed description of case studies. Section "Results and Discussions" explains the simulation results of each PV array interconnection under mismatch effects and then followed by a conclusion in "Conclusion".

\section{PV array Interconnections}

Two kinds of PV array connections are reported in the open literature, divided into conventional and hybrid connections.

\section{Conventional PV Array Interconnections}

As mentioned earlier in "Introduction", various conventional PV array interconnections are reported in the literature to reduce partial shadings such as "simple-series, parallel, series-parallel, total-cross-tied, bridge-link, and honey-

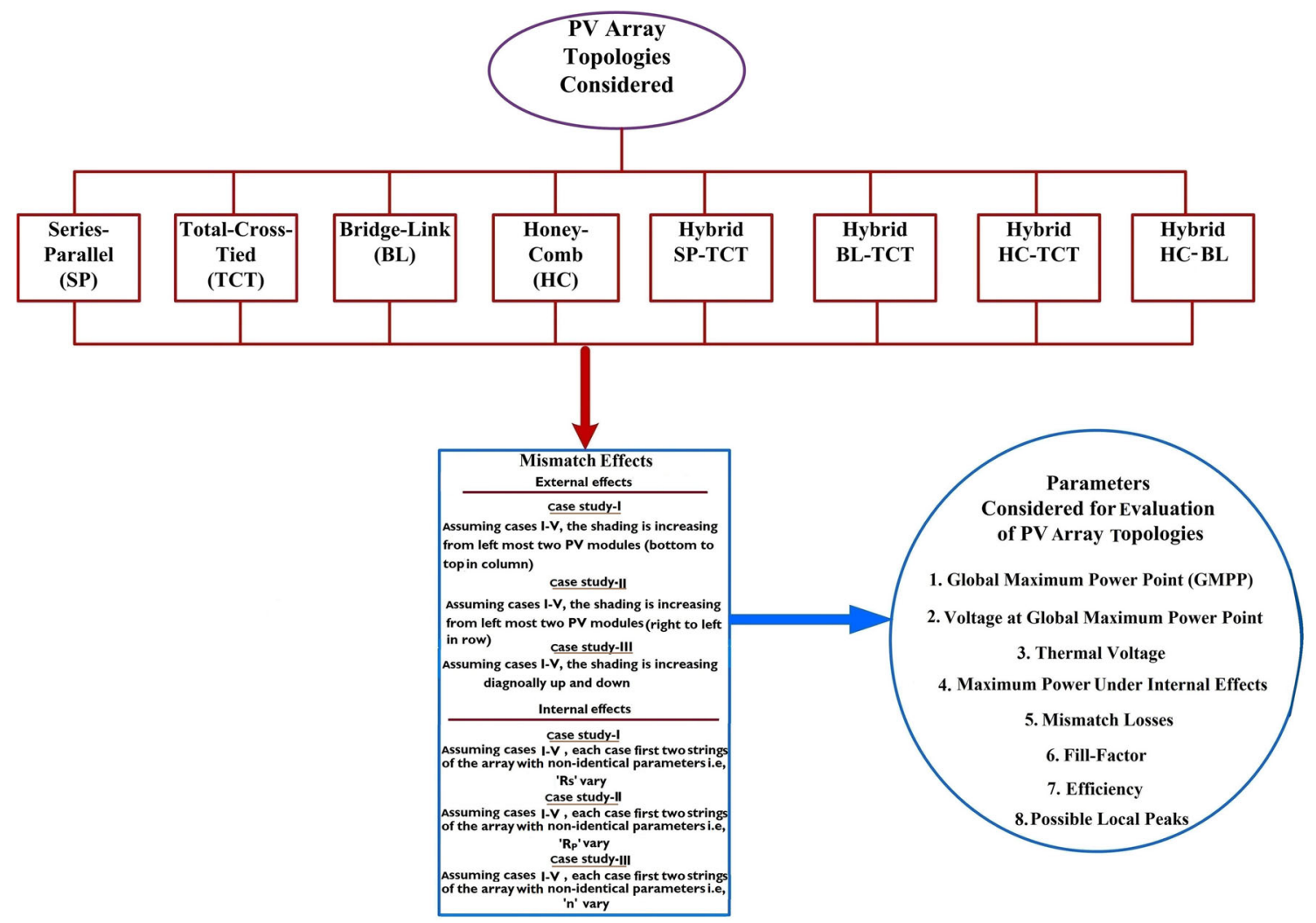

Fig. 1 Various PV array topologies, case studies and acquired parameters 
comb". The general layouts of PV array interconnections are shown in Fig. 2a-f. Among all, the series and parallel connections are designed based on fundamental electrical circuits. In a series connection, PV modules are connected in series to achieve higher voltage (refer in Fig. 2a), and the array current is the same as module current [30]. In parallel connection, PV modules are connected in parallel fashion to build higher current in its output (refer in Fig. 2b), and the array voltage is the same as module voltage. The advantage of parallel connection over series is that the maximum power of the parallel connection is higher than that from the series connection [31]. In series-parallel, first connect PV modules in series to form string so that the module's voltage is summed-up, and many of these strings are connected in parallel to increase the output current (refer in Fig. 2c). This connection is widely used in real-time PV plants because it is effortless to install and also economical. In TCT, connect $\mathrm{PV}$ modules in parallel as a row, which increases the output current, and then many rows are connected in series fashion to increase the output voltage. This connection required more wiring for installation; this would increase the cost. The SP and TCT connections produce the same power value in uniform conditions, and the TCT topology reduces the overall mismatch effect. The bridge-link connection is the same as TCT, but half of the connections are avoided (refer in Fig. 2e), so that cable losses and wiring installation time are reduced $[32,33]$. TCT and BL PV arrays are combined to form the HC connection, as shown in Fig. 2f. In this topology, the modules are interconnected similar to the hexagonal shape.

\section{Hybrid PV array interconnections}

The combination of two conventional array interconnections provides a hybrid connection. In [21], authors introduced hybrid SP-TCT and BL-TCT connections (refer in Fig. $2 \mathrm{~h}$ and g) to examine the effect of PSCs. The SP-TCT connection is the combination of SP and TCT interconnections. Likewise, the BL-TCT connection is the combination of BL and TCT interconnections. Similarly, this paper proposed HC-TCT and HC-BL array interconnections (refer in Fig. 2i and j) to investigate the effect of mismatch.

\section{Modelling of Photovoltaic Array}

A PV cell converts sunlight into electricity (DC) based on the PV effect. A PV cell can generate $0.7 \mathrm{~V} \mathrm{DC}$ and a

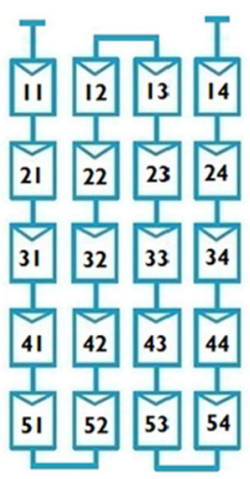

(a)

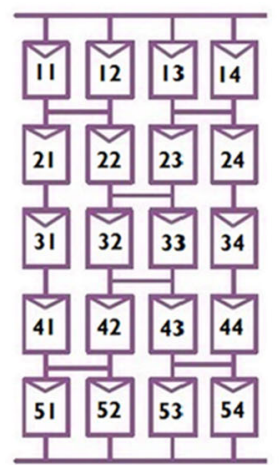

(f)

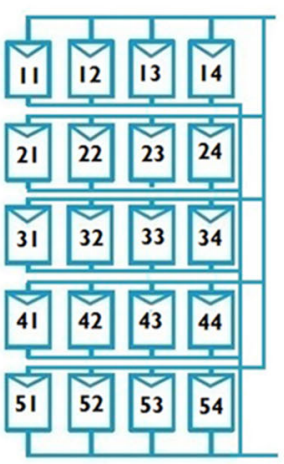

(b)

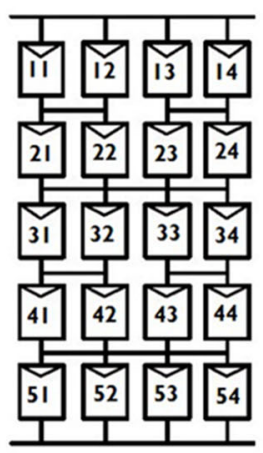

(g)

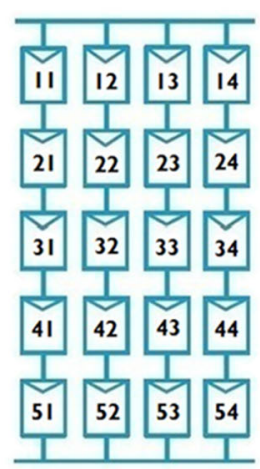

(c)

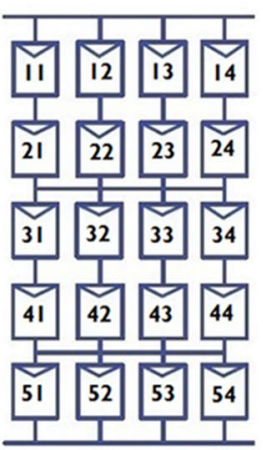

(h)

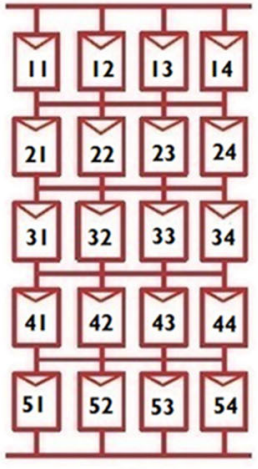

(d)

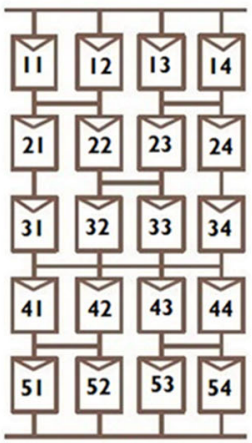

(i)

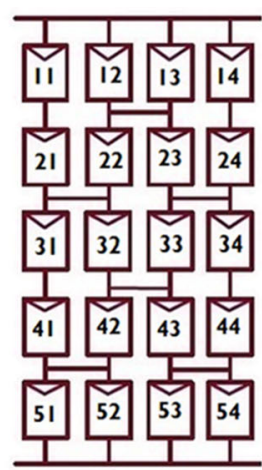

(e)

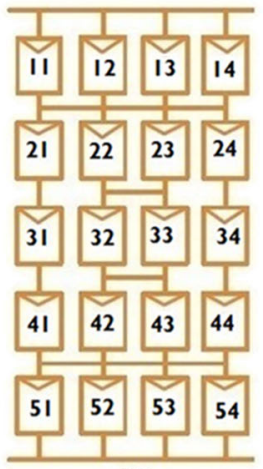

(j)

Fig. 2 Different PV array interconnections;(a) Simple-Series, (b) Parallel, (c) Series-Parallel, (d) Total-Cross-Tied, (e) Bridge-Link, (f) Honey-Comb, (g) hybrid BL-TCT, (h) hybrid SP-TCT, (i) hybrid HC-TCT, (j) hybrid HC-BL 


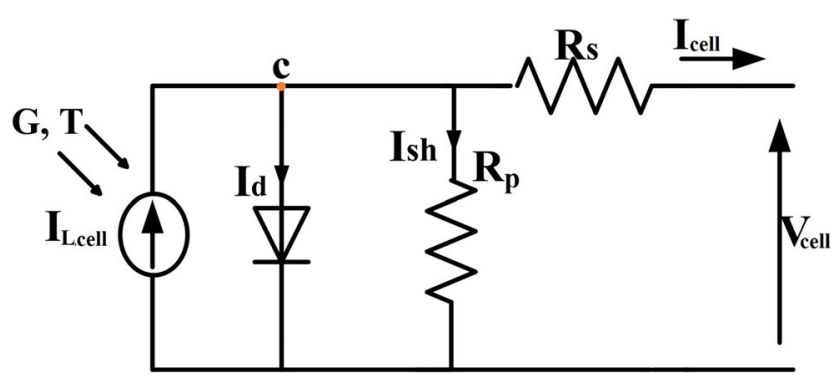

Fig. 3 Circuit diagram of a single diode model

few amperes current at standard test condition (STC) [34]. $\mathrm{PV}$ cells are connected in series to increase the output voltage; this constitutes a PV module. For high power applications, the PV modules are connected in series and parallel, commonly called PV array. Modelling is the first step to analyse the behaviour of the PV system. The PV array modelling starts with the mathematical modelling of a single PV cell. The open-literature reported that the single diode and two diode PV cell models are widely used to study the PV system's performance. As per the literature, the single diode PV cell model is quite easy to modelling than the two diode model [13]. The single diode PV cell equivalent circuit, as shown in Fig. 3.

By applying KCL to node 'c' in Fig. 3, the $I_{\text {cell }}$ can be written as,

$I_{\text {cell }}=I_{L, \text { cell }}-I_{d}-I_{s h}$

where $I_{d}$ is current flowing through the diode and $I_{s h}$ is shunt current of a PV cell,

$$
\begin{array}{r}
I_{d}=I_{o}\left[\exp \left(\frac{V_{d}}{V_{T}}\right)-1\right] \\
I_{s h}=\frac{V_{\text {cell }}+I_{\text {cell }} R_{s}}{R_{p}} \\
V_{T}=\frac{K T_{c}}{q} \times a
\end{array}
$$

where $I_{o}$ is saturation current of PV cell at STC, which can be written as,

$$
I_{o}=I_{d o}\left[\frac{T_{c}}{T_{S T C}}\right]^{3}\left[\operatorname{Exp}\left(\frac{q \cdot E_{g}}{a k}\right)\left(\frac{1}{T_{S T C}}-\frac{1}{T_{c}}\right)\right]
$$

where $I_{d o}$ is reverse saturation current of diode and $E_{g}$ is the band gap energy,

$$
E_{g}=1.16-7.02 \times 10^{-4} \frac{T_{c}^{2}}{T_{c}+1108}
$$

The above set of equations are substituted in Eq.(1), the mathematical equation of I-V characteristics for the PV cell is given by,

$$
\begin{aligned}
I_{\text {cell }}=I_{L, \text { cell }} & -I_{o}\left[\exp \left\{\frac{q\left(V_{\text {cell }}+I_{\text {cell }} R_{s}\right)}{k a T_{c}}-1\right\}\right] \\
& -\left(\frac{V_{\text {cell }}+I_{\text {cell }} R_{s}}{R_{p}}\right)
\end{aligned}
$$

$R_{s}$ and $R_{p}$ are the series and shunt resistances of the PV cell. PV module is composed by connecting number of solar cells in series. The mathematical representation of I-V characteristics for the PV module can be written as,

$$
\begin{aligned}
I_{p v}=I_{L} & -I_{o}\left[\exp \left\{\frac{q\left(V_{p v}+I_{p v} R_{S}\right)}{n_{s} k a T_{c}}-1\right\}\right] \\
& -\left(\frac{V_{p v}+I_{p v} R_{S}}{R_{P}}\right)
\end{aligned}
$$

where $I_{L}$ represents the light generated current of a module,

$I_{L}=\frac{G}{G_{S T C}}\left[I_{L_{S T C}}+K_{i s c}\left(T_{c}-T_{S T C}\right)\right]$

It is worth noticing that Eq. 8 is a transcendental equation, and using this, one can calculate the output current of a PV module. However, Eq. 8 is not limited to single module, and can be expanded to various module connections, called an array (refer in Fig. 4). The numerical expression of I-V characteristics for the PV array is given as follows,

$$
\begin{aligned}
I_{a}=N_{P} \cdot I_{L} & -N_{P} \cdot I_{o}\left[\exp \left\{\frac{q\left(V_{a}+\left(\frac{N_{S}}{N_{P}}\right) I_{a} R_{S}\right)}{n_{s} k a T}-1\right\}\right] \\
& -\left(\frac{V_{a}+\left(\frac{N_{S}}{N_{P}}\right) I_{a} R_{S}}{\left(\frac{N_{S}}{N_{P}}\right) R_{P}}\right)
\end{aligned}
$$

The above set of equations is used to model the output I-V and $\mathrm{P}-\mathrm{V}$ characteristics of the PV array under both uniform

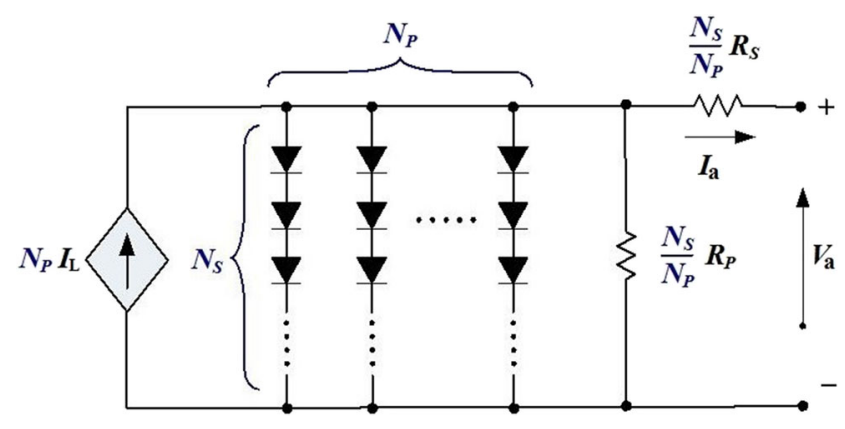

Fig. 4 Equivalent circuit model for PV array 
Table 2 PV module data sheet parameters [21]

\begin{tabular}{ll}
\hline Parameters & Ratings \\
\hline PV Output Power & 170 watts \\
Open Circuit Voltage $\left(V_{o c}\right)$ & 44.2 volts \\
Short Circuit Current $\left(I_{s c}\right)$ & $5.2 \mathrm{amps}$ \\
Current at Maximum Power $\left(I_{m p}\right)$ & $4.75 \mathrm{amps}$ \\
Voltage at Maximum Power $\left(V_{m p}\right)$ & $35.8 \mathrm{volts}$ \\
Number of Cells Connected in Series & 72 \\
Series $\left(R_{s}\right) \&$ Shunt $\left(R_{p}\right)$ Resistance & $0.52 \& 162.2 \mathrm{ohms}$ \\
Ideality factor $(n)$ & 0.96 \\
PV Module Area & $62.2 \mathrm{inc} \times 31.9 \mathrm{inc}$ \\
\hline
\end{tabular}

and partial shading conditions. The PV module data sheet parameters for modelling is listed in Table 2.

\section{Description of Case Studies}

Six case studies are considered to investigate the effect on various PV array interconnections under both internal and external mismatch effects. The external mismatch effects or PSCs are described in "External Mismatch Effects".

\section{External Mismatch Effects}

Case study- $E_{1}$ is divided into five shading cases. In each case, the shadow movement of PV modules increases step by step from bottom to top in the first two columns of the array, as shown by cases $\mathrm{I}-\mathrm{V}$ in Fig. 5.

Case study- $E_{2}$ is divided into five shading cases. In each case, the shadow movement of PV modules increases step by step from left to right in the last two rows of the array, as shown by cases $\mathrm{I}-\mathrm{V}$ in Fig. 6.
Case study- $E_{3}$ is divided into five shading cases. In each case, the shadow movement of PV modules fluctuates up and down diagonally in the array, as shown by cases I-V in Fig. 7.

\section{Internal Mismatch Effects}

As described in "Introduction", the probability of series resistance $\left(R_{S}\right)$, shunt resistance $\left(R_{S h}\right)$ and ideality factor (a) parameters mismatch is high in manufacturing, affecting the PV array's power output and fill factor [12]. Three case studies are taken into account to examine the effect of internal mismatch on PV arrays. Each case, it is assumed that one of the parameters (i.e., $R_{S}, R_{P}, a$ ) varies $15 \%$ (i.e., regarded as critical degradation of PV module) of its actual value [12].

- Case study- $I_{1}$ is divided into five cases I-V. In each case, the $R_{S}$ of PV modules increased to $15 \%$ of its actual value in the first two string of the $5 \times 4 \mathrm{PV}$ arrays, as shown in Fig. 8.

- Case study- $I_{2}$ is divided into five cases I-V. In each case, the $R_{P}$ of $\mathrm{PV}$ modules decreased to $15 \%$ of its actual value in the first two string of the $5 \times 4 \mathrm{PV}$ arrays, as shown in Fig. 8.

- Case study- $I_{3}$ is divided into five cases I-V. In each case, the $a$ of PV modules decreased to $15 \%$ of its actual value in the first two string of the $5 \times 4 \mathrm{PV}$ arrays, as shown in Fig. 8.

\section{Description of Acquired Parameters}

\section{Fill factor}

Fill-factor is an index, which measures the squareness of I$\mathrm{V}$ characteristics of the PV array. This can be obtained as;

\begin{tabular}{|l|l|l|l|}
\hline$I I$ & $I 2$ & $I 3$ & $I 4$ \\
\hline $2 I$ & 22 & 23 & 24 \\
\hline $3 I$ & 32 & 33 & 34 \\
\hline $4 I I$ & 42 & 43 & 44 \\
\hline $5 I I$ & 52 & 53 & 54 \\
\hline
\end{tabular}

Case-I

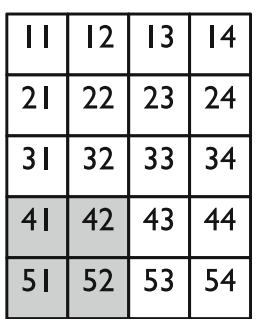

Case-II

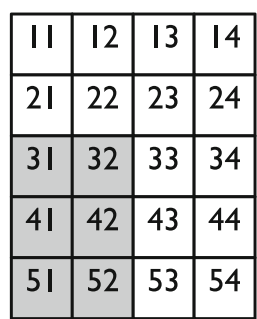

Case-III

\begin{tabular}{|l|l|l|l|}
\hline$I I$ & 12 & 13 & 14 \\
\hline 21 & 22 & 23 & 24 \\
\hline $3 I$ & 32 & 33 & 34 \\
\hline $4 I$ & 42 & 43 & 44 \\
\hline $5 I$ & 52 & 53 & 54 \\
\hline
\end{tabular}

Case-IV

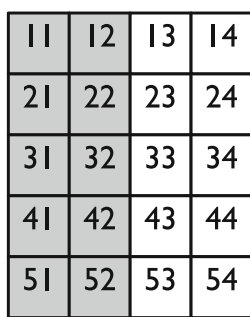

Case-V

$=400 \mathrm{~W} / \mathrm{m}^{2}$

Fig. 5 Case study- $E_{1}$ for external mismatch effects 


\begin{tabular}{|l|l|l|l|}
\hline 11 & 12 & 13 & 14 \\
\hline 21 & 22 & 23 & 24 \\
\hline 31 & 32 & 33 & 34 \\
\hline $4 I$ & 42 & 43 & 44 \\
\hline 51 & 52 & 53 & 54 \\
\hline
\end{tabular}

Case-I

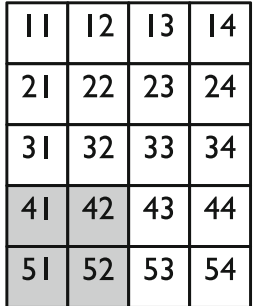

Case-II

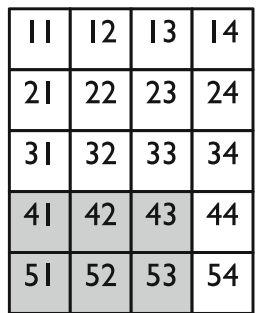

Case-III

\begin{tabular}{|l|l|l|l|}
\hline$I I$ & 12 & 13 & 14 \\
\hline $2 I$ & 22 & 23 & 24 \\
\hline $3 I$ & 32 & 33 & 34 \\
\hline $4 I$ & 42 & 43 & 44 \\
\hline $5 I$ & 52 & 53 & 54 \\
\hline
\end{tabular}

Case-IV

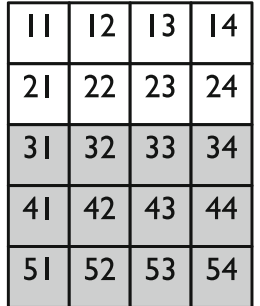

Case-V

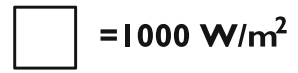

$=400 \mathrm{~W} / \mathrm{m}^{2}$

Fig. 6 Case study- $E_{2}$ for external mismatch effects

$F F=\frac{\text { Power at GMPP }}{V_{o c} \cdot I_{s c}}$

\section{Thermal Voltage}

Thermal voltage is the relationship between electrical current flow and the voltage across the PV module. This can be obtained as;

$V_{T}=\frac{\left(2 V_{m p}-V_{o c}\right)\left(I_{s c}-I_{m p}\right)}{I_{m p}-\left(I_{s c}-I_{m p}\right) \ln \left(\frac{I_{s c}-I_{m p}}{I_{s c}}\right)}$

\section{Power Losses}

Power loss (PL) is the difference between the maximum power at uniform irradiance condition and the global maximum power at PSCs. This can be obtained as;

$$
P L=M P P_{u n i}-G M P P_{P S C s}
$$

\section{Possible Local Peaks}

In PSC, PV array exhibits multiple peaks in P-V characteristics. Only one global peak (GP) exists among numerous peaks, and the remaining peaks are referred to as local peaks (LPs). From the observation of output P-V characteristics, the possible local peaks within each PV array connection are known.

\section{Efficiency}

The efficiency of a PV system is defined as the ratio of maximum power output to the input solar power and is calculated by using Eq. 14

$\operatorname{Efficiency}(\eta)=\frac{\text { Power at } G M P P}{P_{i n}}$

where $P_{i n}$ is solar irradiance falls on the PV array.

\section{Results and Discussions}

In this article, eight different $5 \times 4 \mathrm{PV}$ array interconnections are considered, such as SP, TCT, BL, HC, SP-TCT, BLTCT, HC-TCT, and HC-BL, to investigate the performance under internal and external mismatch effects. Six case studies relating to both internal and external mismatch situations are taken into consideration. In each case, the GMPP, $V_{G M P P}, V_{T H}, \mathrm{PL}, \mathrm{FF}, \eta$, and PLP parameters are obtained and compared for PV array interconnections.

\begin{tabular}{|l|l|l|l|}
\hline$I I$ & $I 2$ & $I 3$ & $I 4$ \\
\hline $2 I$ & 22 & 23 & 24 \\
\hline $3 I$ & 32 & 33 & 34 \\
\hline $4 I$ & 42 & 43 & 44 \\
\hline $5 I$ & 52 & 53 & 54 \\
\hline
\end{tabular}

Case-I

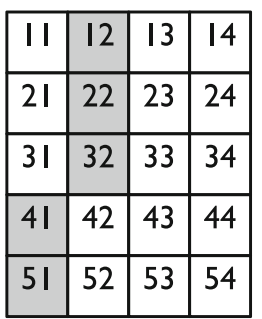

Case-II

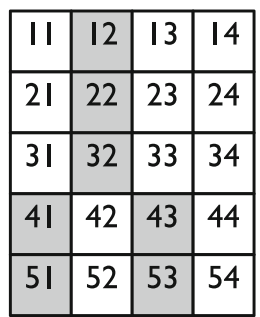

Case-III

\begin{tabular}{|l|l|l|l|}
\hline$I I$ & $I 2$ & $I 3$ & 14 \\
\hline $2 I$ & 22 & 23 & 24 \\
\hline $3 I$ & 32 & 33 & 34 \\
\hline $4 I$ & 42 & 43 & 44 \\
\hline $5 I$ & 52 & 53 & 54 \\
\hline
\end{tabular}

Case-IV

\begin{tabular}{|l|l|l|l|}
\hline$I I$ & 12 & 13 & 14 \\
\hline 21 & 22 & 23 & 24 \\
\hline 31 & 32 & 33 & 34 \\
\hline $4 I$ & 42 & 43 & 44 \\
\hline 51 & 52 & 53 & 54 \\
\hline
\end{tabular}

Case-V

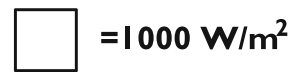

$=400 \mathrm{~W} / \mathrm{m}^{2}$

Fig. 7 Case study- $E_{3}$ for external mismatch effects 


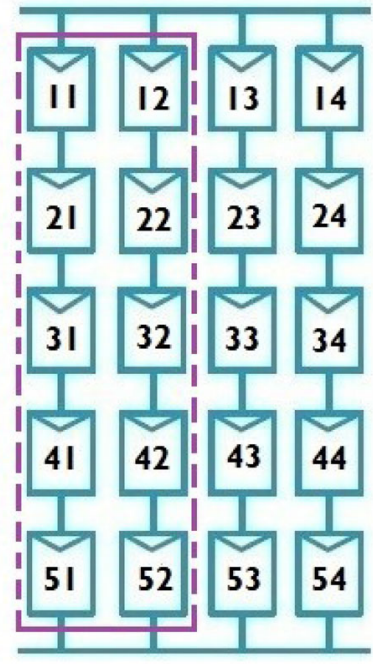

Fig. 8 First two strings with non-identical parameters

\section{External Mismatch Effects or PSCs}

\section{Investigation of PV array connections under case study-E1}

The $\mathrm{P}-\mathrm{V}$ characteristics of $\mathrm{PV}$ array connections for shading cases I-V in case study- $E_{1}$ are shown in Figs. 9, 10 and 11. In shading case-I, multiple peaks are observed on the $\mathrm{P}-$ $\mathrm{V}$ curve, as shown in Fig. 9a. It is noticed from the figure that the local peaks of all interconnections are very near to the global peaks. In shading case-I, the SP and BL-TCT PV arrays produced true GMPP, which can be observed in Table 3. The $\mathrm{P}-\mathrm{V}$ characteristics of array interconnections for shading case-II, as shown in Fig. 9b. It is noted from the figure that the local peaks of array connections are far from the global peaks. Whereas, in this case, the TCT and HCTCT PV arrays produced true GMPP showed in Table 3. Figure $10 \mathrm{a}$ and $\mathrm{b}$ shows the output $\mathrm{P}-\mathrm{V}$ characteristics for shading case-III and case-IV. In case-III, multiple peaks

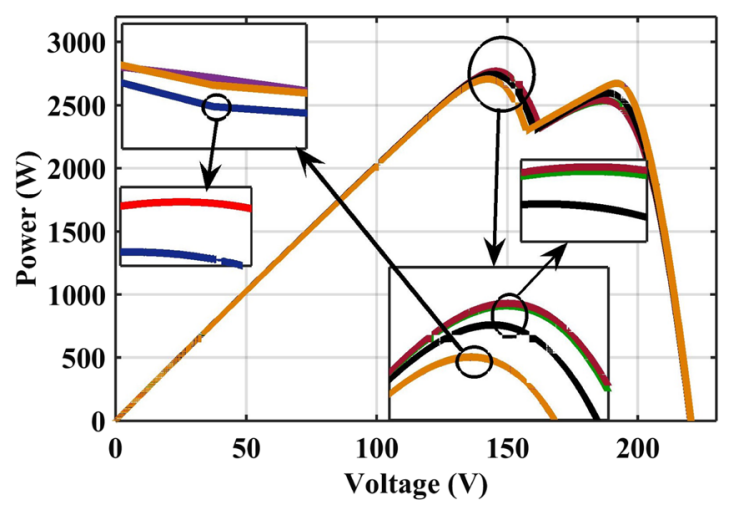

are noted on the P-V curve. It is indicated from the figure that the local peaks are far from the global peaks. In this case, TCT, BL-TCT, and SP-TCT PV arrays produced true GMPP. In case-IV, the location of local peaks is far from the global peaks, as shown in Fig. 10b. In this case, the TCT, BL, and HC-BL PV arrays produced true GMPP. The P-V characteristics of array connections for shading case- $\mathrm{V}$, as shown in Fig. 11. In this case, PV arrays produced equal GMPP listed in Table 3.

From case study- $E_{1}$, it is observed that if the shading effect increased, then the GMPP of all array interconnections decreased for shading cases I-V. Under this study, the obtained parameters such as GMPP, $V_{G M P P}$, and $V_{T H}$ are presented in Table 3. Also, the other parameters such as PL, FF, $\eta$, and PLP are given in Table 4 . It is found from the table that the TCT PV array produced the highest GMPP as compared to the other connections under most shading cases.

\section{Investigation of PV array interconnections under case study-E2}

The $\mathrm{P}-\mathrm{V}$ characteristics of $\mathrm{PV}$ array connections for shading cases $\mathrm{I}-\mathrm{V}$ in case study- $E_{2}$ are shown in Figs. 12, 13 and 14. In case-I, multiple peaks are observed on the P-V curve. It is noted from the figure that the local peaks are far from the global peaks, as shown in Fig. 12a. Whereas, in this case, the TCT and HC-TCT PV arrays produced true GMPP, which can be observed in Table 5 . The $\mathrm{P}-\mathrm{V}$ characteristics of array interconnections for shading case-II, as shown in Fig. 12b. From the figure, it is noted that the local peaks are far from the global peaks. For this case, the TCT and HC-TCT PV arrays produced true GMPP listed in Table 5. The $\mathrm{P}-\mathrm{V}$ characteristics for shading case-III and case-IV are shown in Fig. 13a and $\mathrm{b}$ respectively. Multiple peaks are noted on the $\mathrm{P}-\mathrm{V}$ curve for shading case-III, as shown in Fig. 13a. From the figure, it is noticed that the local peaks

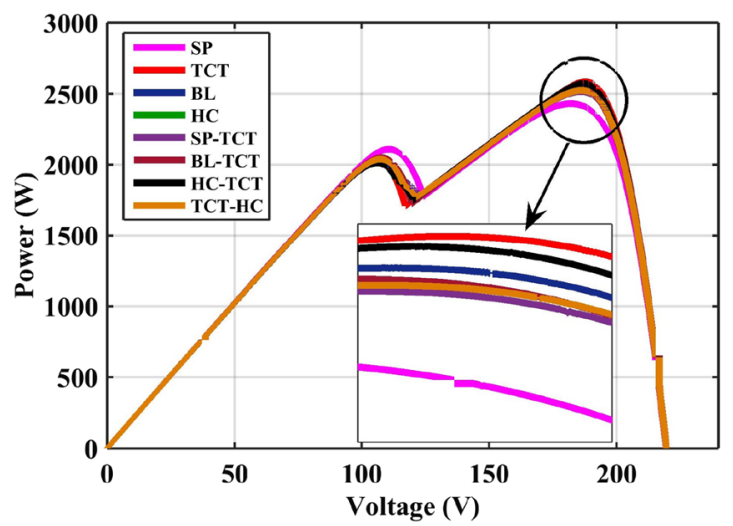

Fig. 9 PV array characteristics for case study- $E_{1}$ 

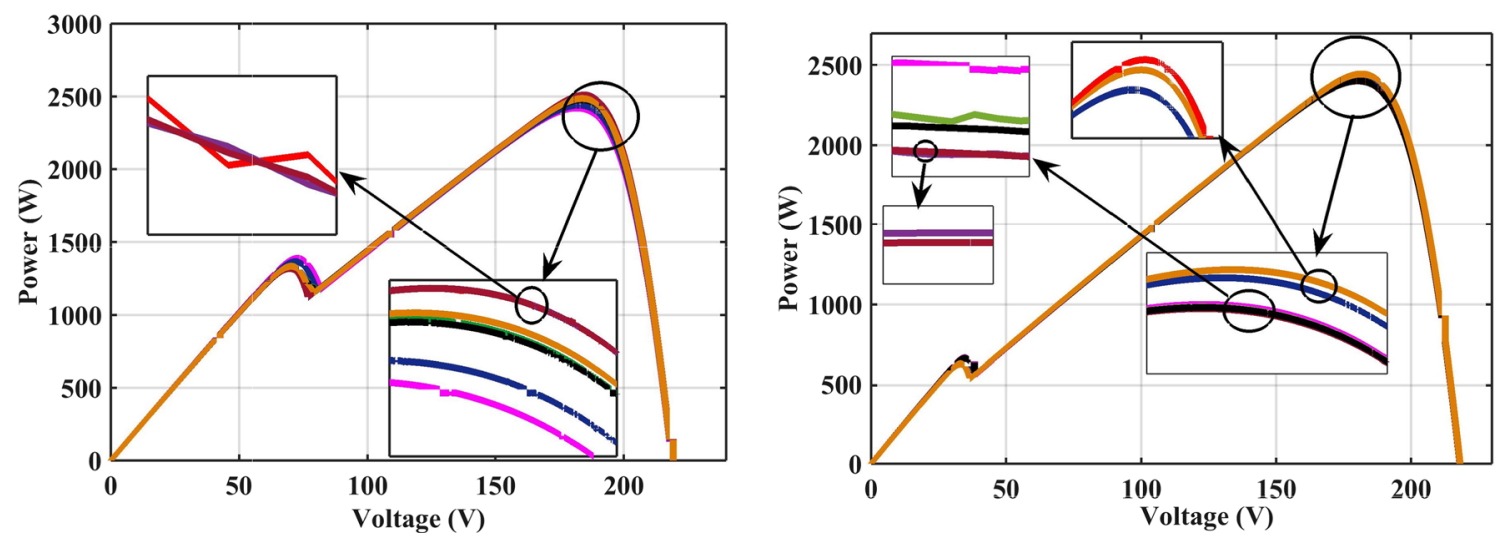

Fig. $10 \mathrm{PV}$ array characteristics for case study- $E_{1}$

are far from the global peaks. In this case, the TCT and HCTCT PV arrays produced true GMPP. In case-IV, the local peaks are far from the global peaks, which can be seen in Fig. 13b. In this case, the PV arrays produced equal GMPP listed in Table 5. In case- $\mathrm{V}$, multiple peaks are observed on the P-V curve, as shown in Fig. 14. The location of local peaks is far from global peaks in this shading case. The GMPP of PV array connections is identical in this case.

From case study- $E_{2}$, it is noted that if the shading effect increased, then the GMPP of all array interconnections decreased for shading cases I-V. Under this case study, the obtained parameters such as GMPP, $V_{G M P P}$ and $V_{T H}$ are presented in Table 5. Also, the other parameters such as PL, FF, $\eta$, and PLP are given in Table 6. It is found from the table that the TCT/HC-TCT PV array produced the highest GMPP as compared to the other connections under all shading cases.

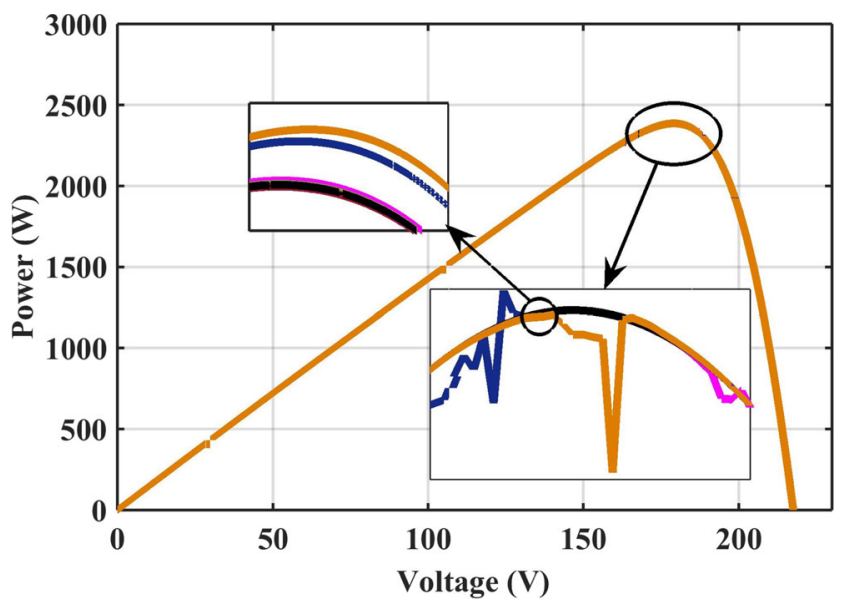

Fig. $11 \mathrm{P}-\mathrm{V}$ characteristics for case-V in case study- $E_{1}$

\section{Investigation of PV array interconnections under case study-E3}

The P-V characteristics of PV array interconnections for shading cases I-V in case study- $E_{3}$ are shown in Figs. 15, 16 and $17 \mathrm{a}$. For shading case-I, various multiple peaks are noted on the P-V curve, as shown in Fig. 15a, From the figure, it is found that the local peaks are far from the global peaks. Whereas, in this case, the TCT and HC-TCT $\mathrm{PV}$ arrays produced true GMPP listed in Table 7. The P-V characteristics of array interconnections for shading caseII, as shown in Fig. 15b. It is noted from the figure that the local peaks are far from the global peaks. In this case, the TCT PV array is produced true GMPP. Figure 16a and $\mathrm{b}$ depicts the P-V characteristics for shading case-III and case-IV, respectively. Figure 16a shows that multiple peaks exist on the P-V curve for shading case-III. It is noted from the figure that the location of local peaks is at a distance from the global peaks. In this case, the TCT PV array produced true GMPP. In case-IV, the conventional and hybrid PV array connections are displayed various peaks on the P-V curve. Among all, the TCT PV array is produced true GMPP is listed in Table 7. Similarly, for case- $\mathrm{V}$, the $\mathrm{P}-\mathrm{V}$ curve indicates multiple peaks, as shown in Fig. 17a. In this case, the TCT, BL-TCT, and HC-TCT PV arrays produced real GMPP, which can be observed in Table 7.

From case study- $E_{3}$, it is noted that if the shading effect increased, then the GMPP of all array interconnections decreased for shading cases I-V. Under this case study, the obtained parameters such as GMPP, $V_{G M P P}$ and $V_{T H}$ are presented in Table 7. Also, the other parameters such as PL, FF, $\eta$, and PLP are given in Table 8. It is found from the table that the TCT PV array produced the highest GMPP as compared to the other interconnections under all shading cases. 


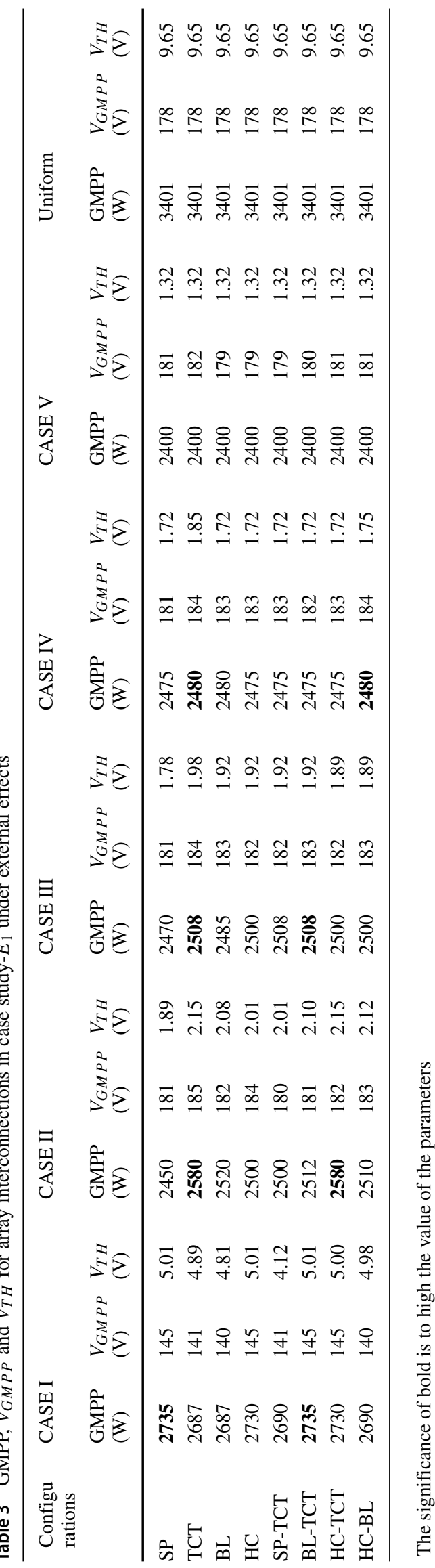

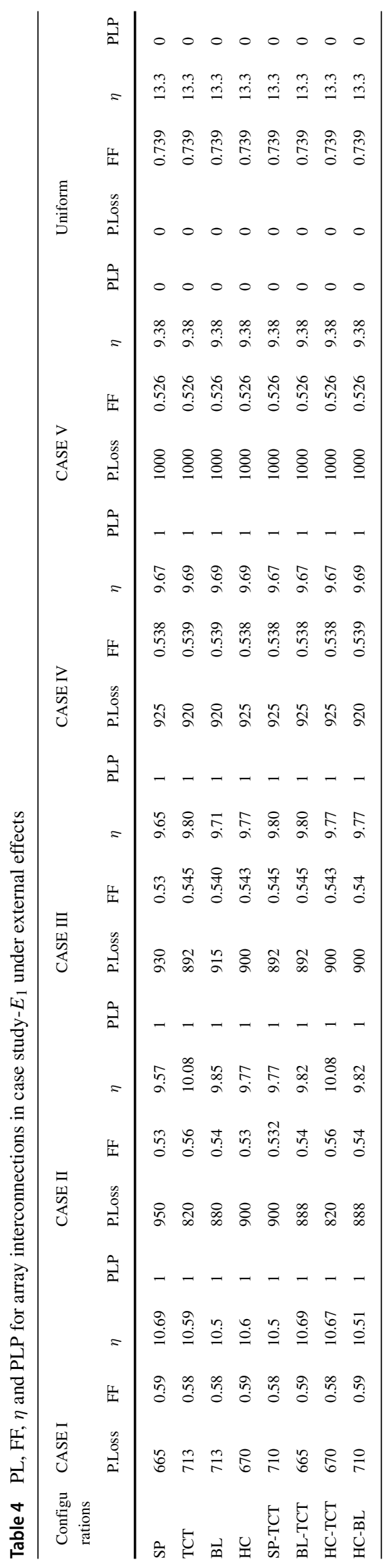




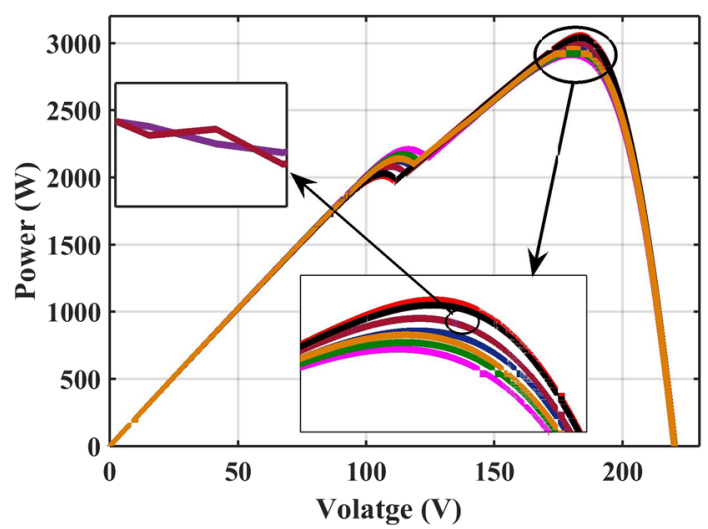

(a) P-V characteristics for case-I

Fig. $12 \mathrm{PV}$ array characteristics for case study- $E_{2}$

\section{Internal Mismatch Effects}

\section{Investigation of PV array interconnections under case study-11}

Case study- $I_{1}$ is divided into five sub-cases I-V. In each case, the $R_{S}$ of PV modules increased to $15 \%$ of its actual value in the first two strings of the PV arrays (refer in Fig. 8). In case-I, the $R_{S}$ is increased to $15 \%$ of its actual value, i.e., 0.52 to 0.59 in the PV arrays. In this case, the TCT array is produced real maximum power is listed in Table 9. In case-II, the $R_{S}$ is increased to $30 \%$ of its actual value, i.e., 0.52 to 0.67 in the PV arrays. For this case, the TCT and HC-BL PV arrays produced real maximum power is showed in Table 9. In case-III \& IV, the $R_{S}$ is increased to $45 \%$ \& $60 \%$ of its actual values, respectively. The generated real maximum powers of case-III \& case-IV are given in Table 9. In case-V, the $R_{S}$ is increased to $75 \%$ of its actual value, i.e., 0.52 to 0.92 in the PV arrays. In this case, the TCT array is produced real maximum power, which can be observed in Table 9 .

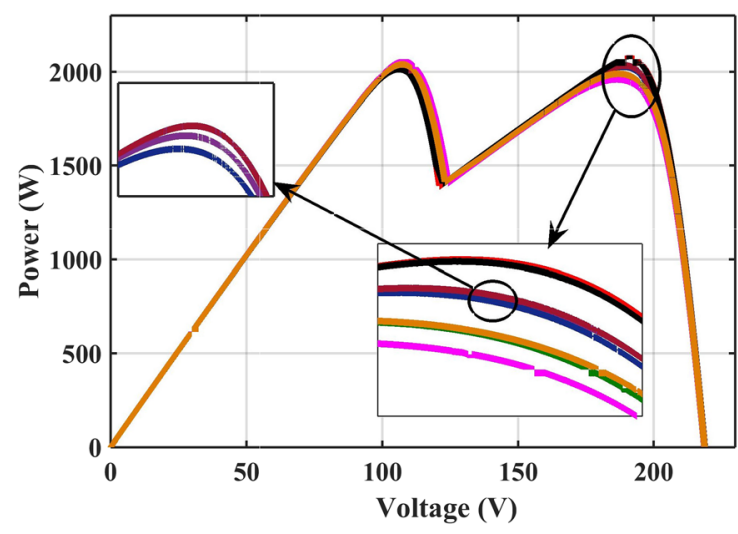

(a) P-V characteristics for case-III

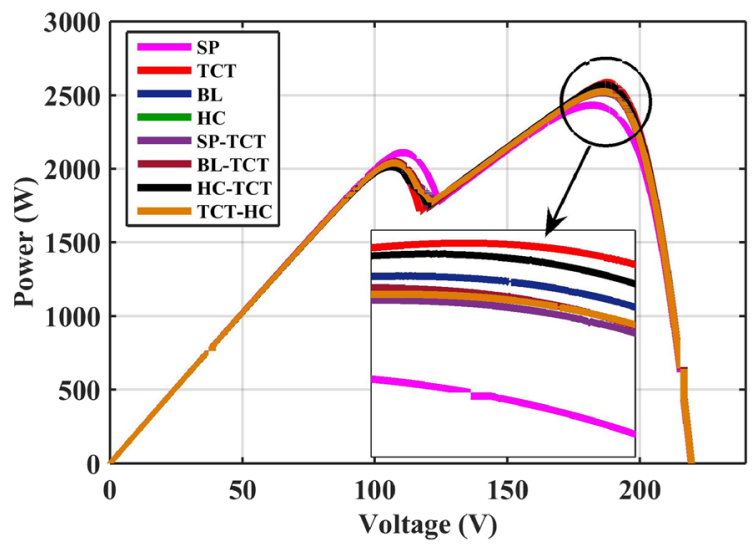

(b) P-V characteristics for case-II

From case study- $I_{1}$, it is noted that increasing the series resistance of the PV modules decreased the maximum power production and voltage of the array interconnections. Under this study, the obtained parameters such as GMPP, $V_{G M P P}$ and $V_{T H}$ are presented in Table 9. Also, the other parameters such as PL, FF, $\eta$, and PLP are given in Table 10. It is found from the table that the TCT array is produced the highest maximum power as compared to the other interconnections in most cases.

\section{Investigation of PV array interconnections under case study-12}

Case study- $I_{2}$ is divided into five sub-cases I-V. In each case, the $R_{P}$ of PV modules decreased to $15 \%$ of its actual value in the first two strings of the PV arrays (refer in Fig. 8). In case-I, the $R_{P}$ is decreased to $15 \%$ of its actual value, i.e., 162.2 to 137.8 in the PV arrays. In this case, the TCT and HC-BL PV arrays produced real maximum power is listed in Table 11. In case-II, the $R_{P}$ is decreased to $30 \%$ of its actual value, i.e.,

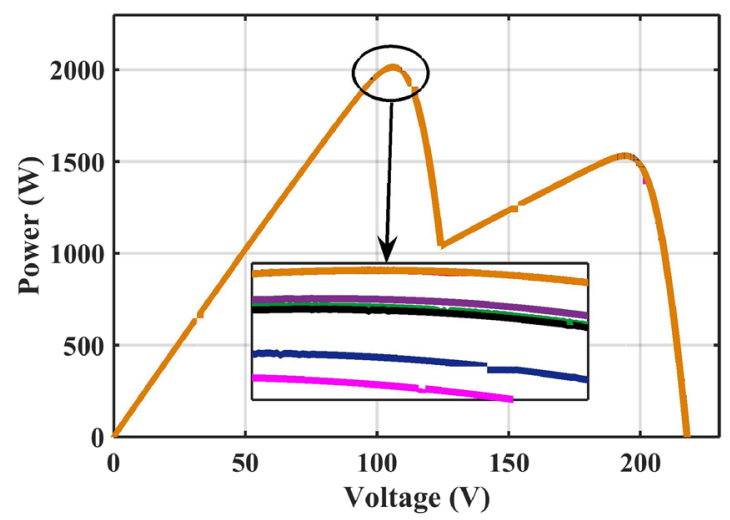

(b) P-V characteristics for case-IV

Fig. $13 \mathrm{PV}$ array characteristics for case study- $E_{2}$ 


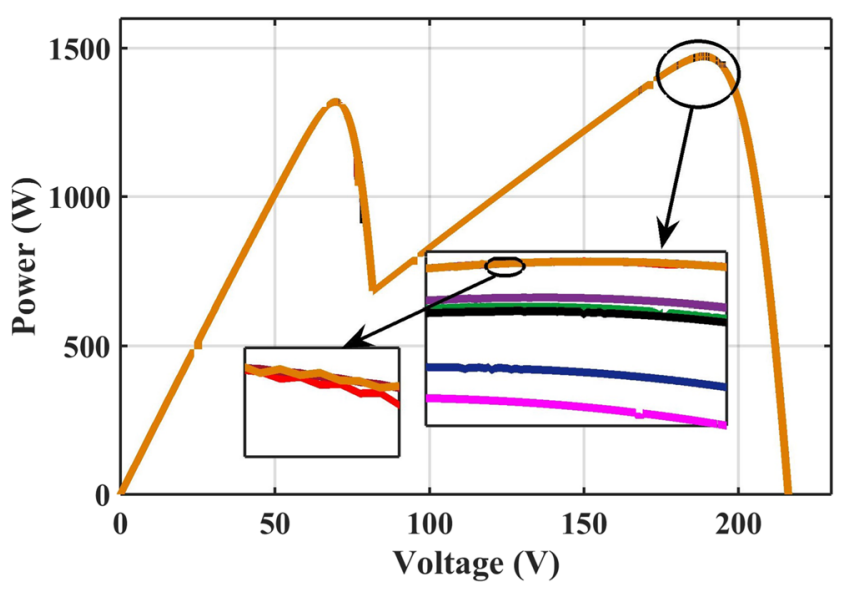

Fig. $14 \mathrm{P}-\mathrm{V}$ characteristics for case- $\mathrm{V}$ in case study- $E_{2}$

162.2 to 113.5 in the PV arrays. In this case, the TCT and HC PV arrays produced real maximum power. In case-III \& IV, the $R_{P}$ is decreased to $45 \% \& 60 \%$ of its actual values, respectively. The generated real maximum powers of caseIII \& case-IV are given in Table 11 . In case-V, the $R_{P}$ is decreased to $75 \%$ of its actual value, i.e., 162.2 to 50.5 in the PV arrays. For this case, the TCT array is produced real maximum power is given in Table 11.

From case study- $I_{2}$, it is noted that decreasing the shunt resistance of the PV modules decreased the maximum power production and voltage of the array interconnections. Under this case study, the obtained parameters such as GMPP, $V_{G M P P}$ and $V_{T H}$ are presented in Table 11. Also, the other parameters such as PL, FF, $\eta$, and PLP are given in Table 12. It is found from the table that the TCT and HC PV arrays produced the highest GMPP as compared to the other interconnections in most cases.

\section{Investigation of PV array interconnections under case study-13}

Case study- $I_{3}$ is divided into five sub-cases I-V. In each case, the ideality factor $(a)$ of $\mathrm{PV}$ modules decreased to $15 \%$ of its actual value in the first two strings of PV array interconnections (refer in Fig. 8). In case-I, the $n$ is decreased to $15 \%$ of its actual value, i.e., 0.96 to 0.81 in the PV arrays. In this case, the TCT and HC-BL PV arrays produced real maximum power listed in Table 13. In case-II, the $n$ is decreased to $30 \%$ of its actual value, i.e., 0.96 to 0.67 in the PV arrays. In this case, the TCT and HC PV arrays produced real maximum power. In case-III $\& \mathrm{IV}$, the $n$ is decreased to $45 \% \& 60 \%$ of its actual values, respectively. The generated real maximum powers of case-III \& case-IV are given in Table 11. In case- $\mathrm{V}$, the $n$ is decreased to $75 \%$ of its actual value, i.e., 0.96 to 0.25 in the PV arrays. In this case, the real maximum power produced by the TCT array.

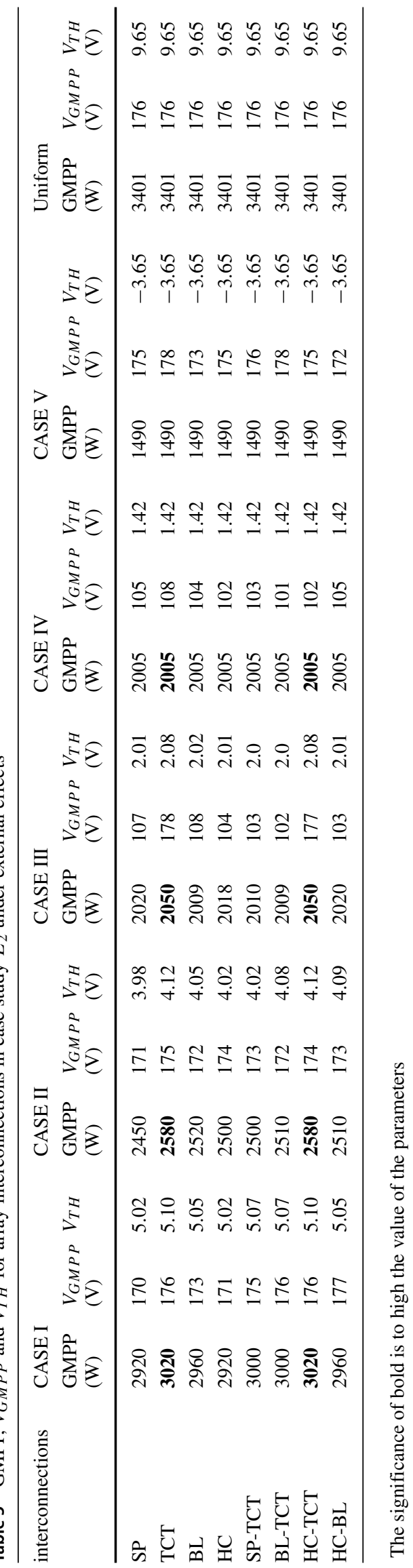




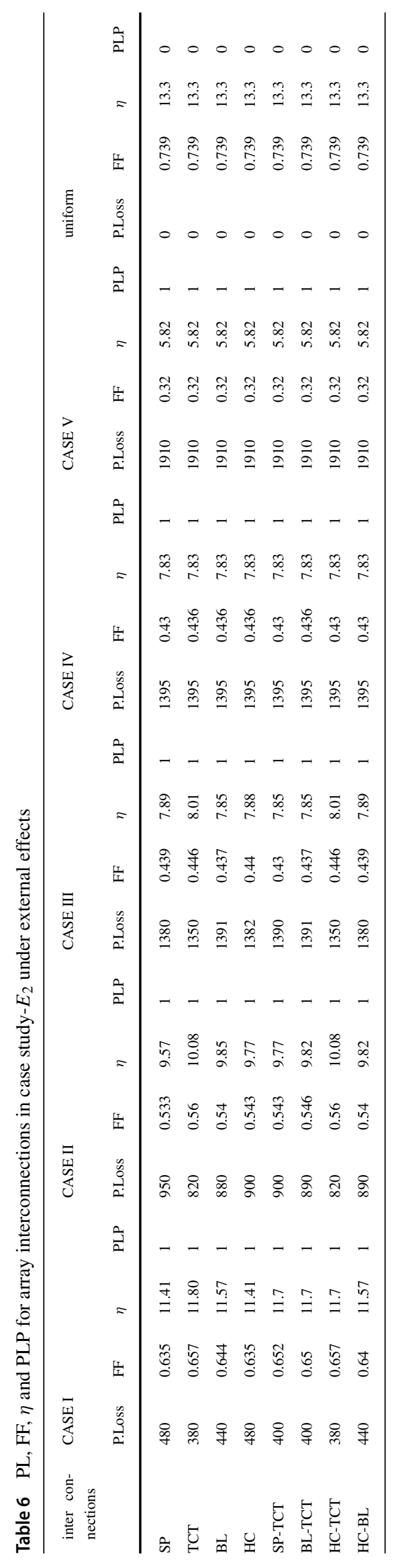




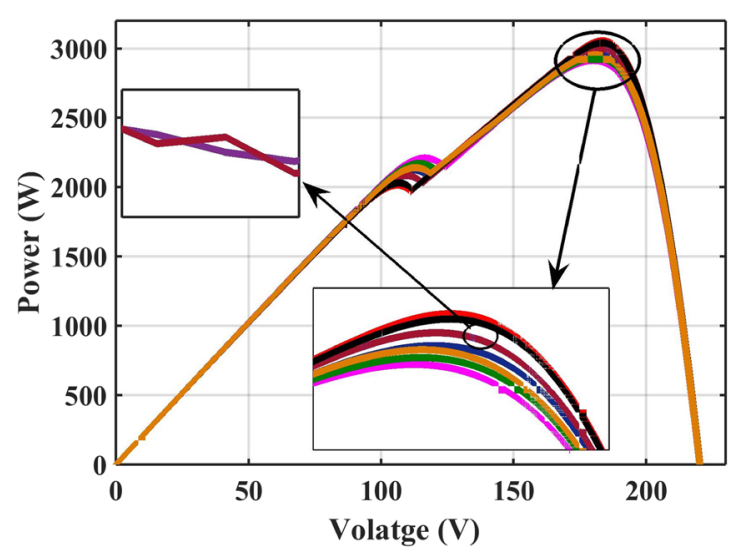

(a) P-V characteristics for case-I

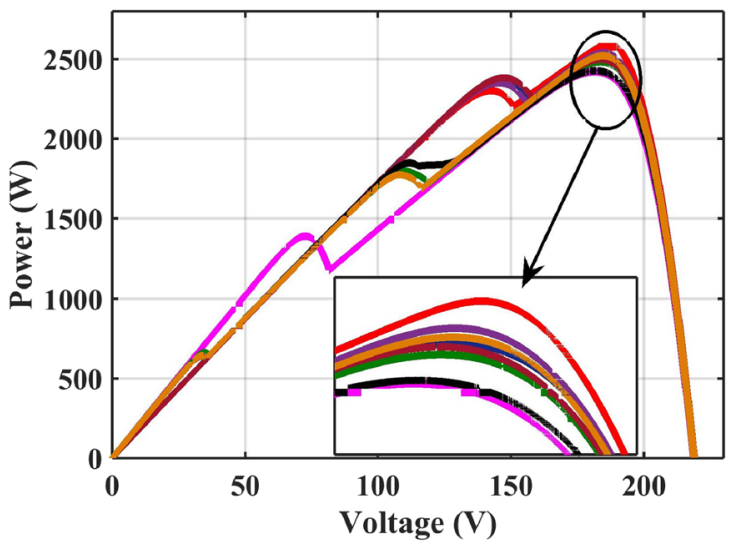

(b) P-V characteristics for case-II

Fig. $15 \mathrm{PV}$ array characteristics for case study- $E_{3}$

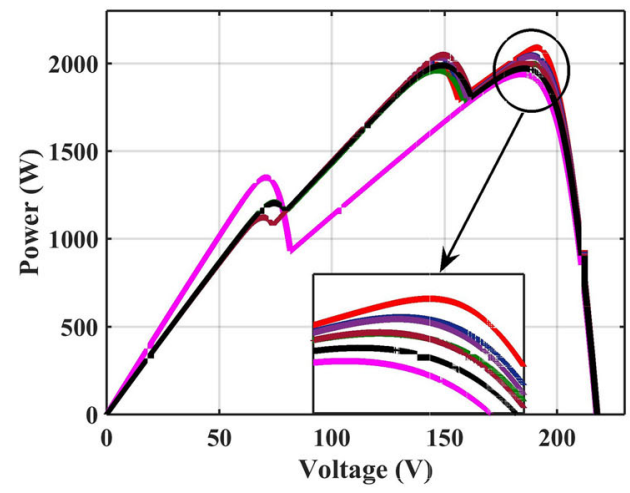

(a) P-V characteristics for case-III

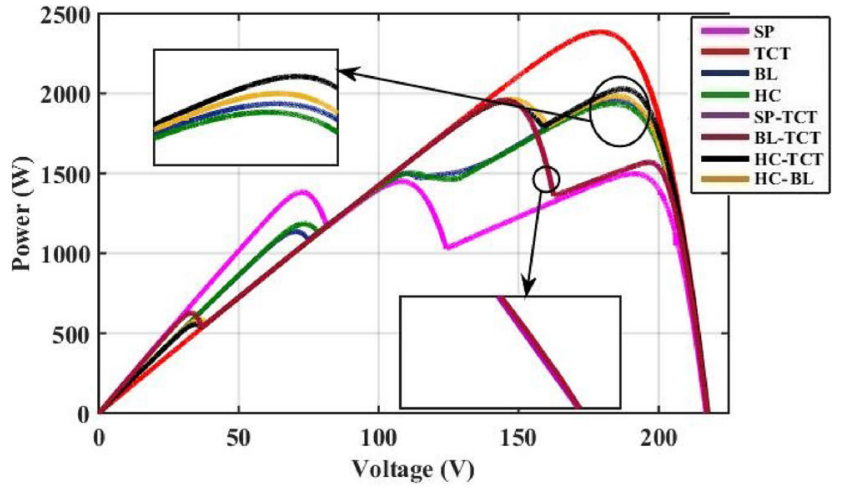

(b) P-V characteristics for case-IV

Fig. $16 \mathrm{PV}$ array characteristics for case study- $E_{3}$

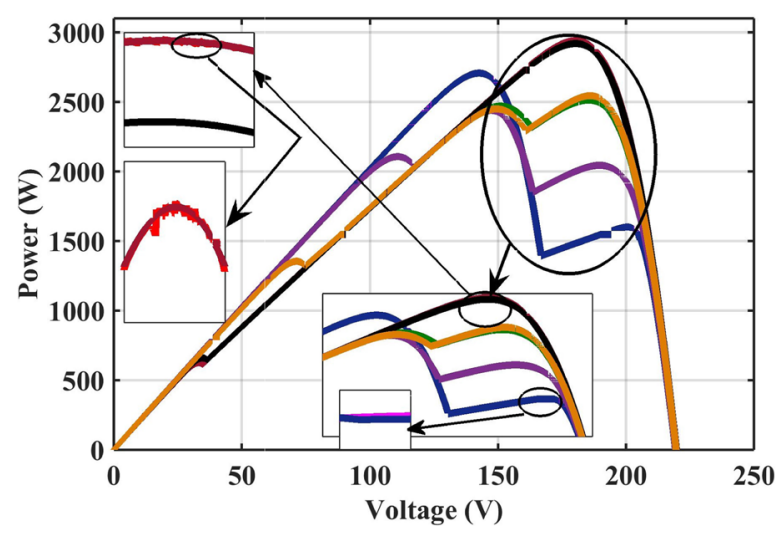

(a) $\mathrm{P}-\mathrm{V}$ characteristics for case- $\mathrm{V}$ in case study- $E_{3}$

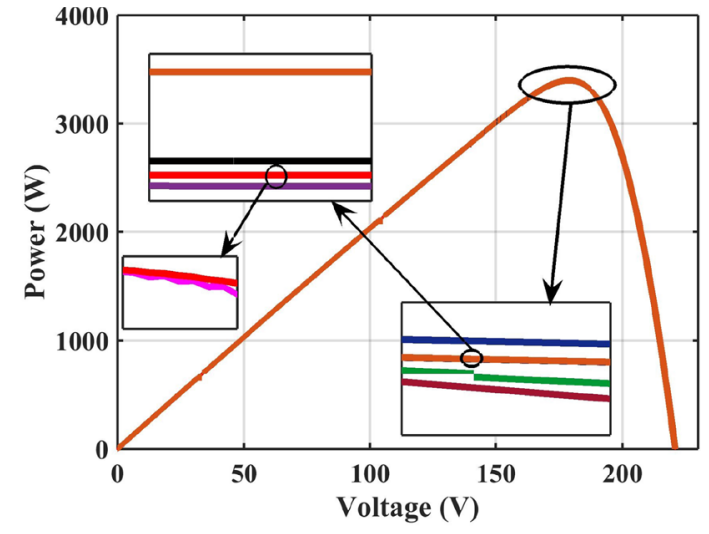

(b) P-V characteristics for uniform condition

Fig. $17 \mathrm{PV}$ array characteristics for case- $\mathrm{V}$ in case study- $E_{3}$ and uniform condition 

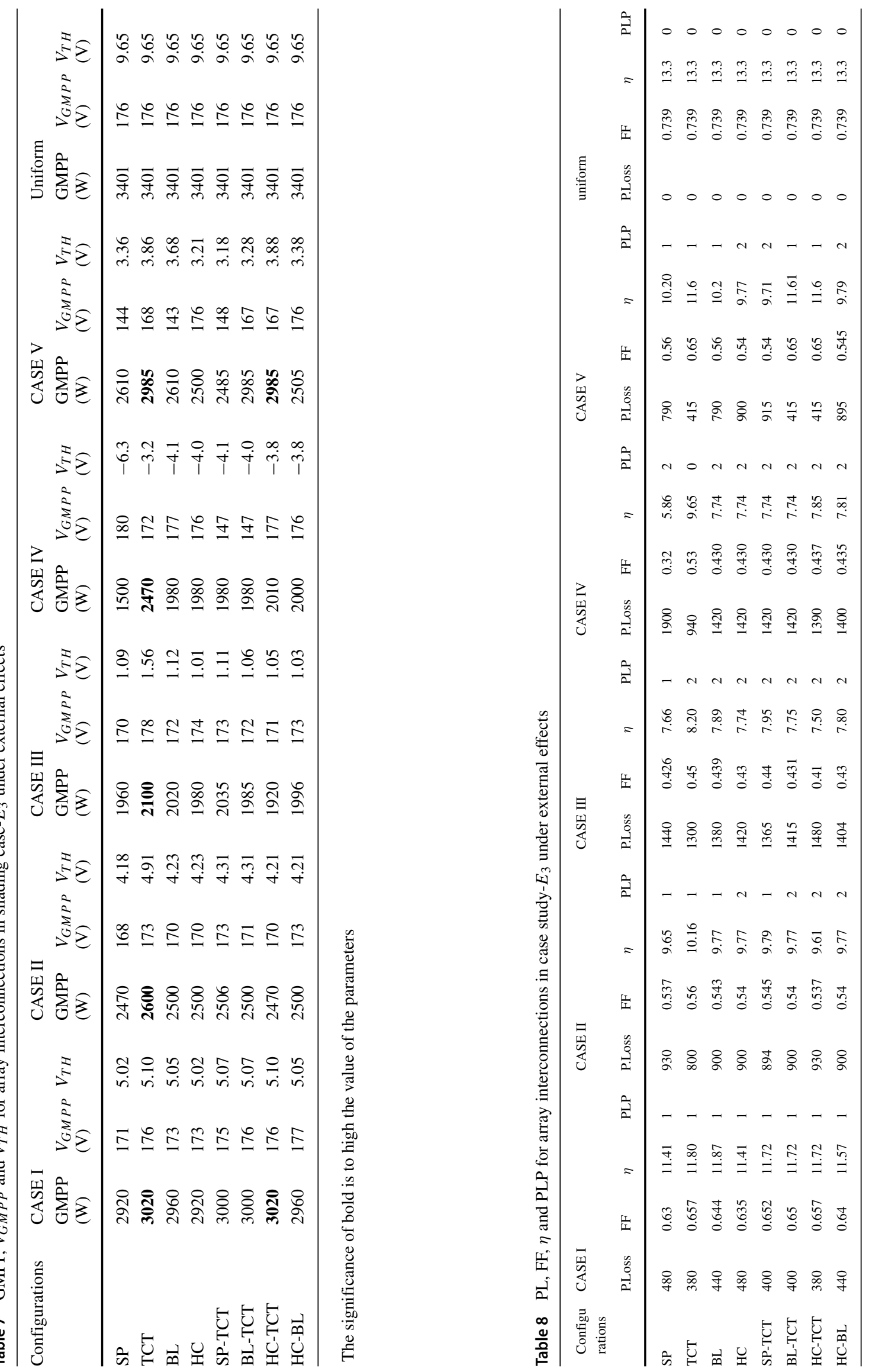


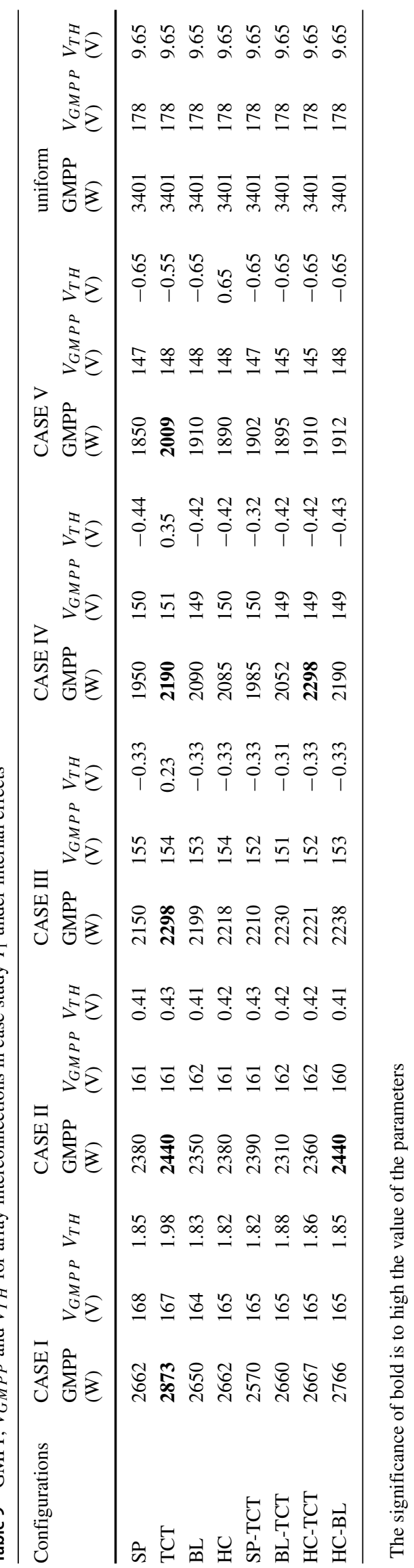

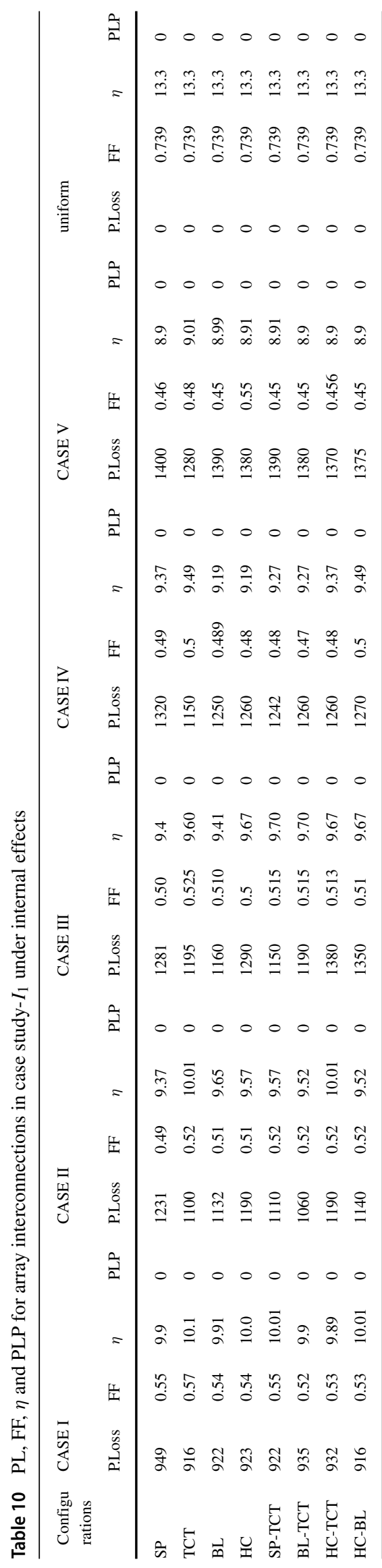



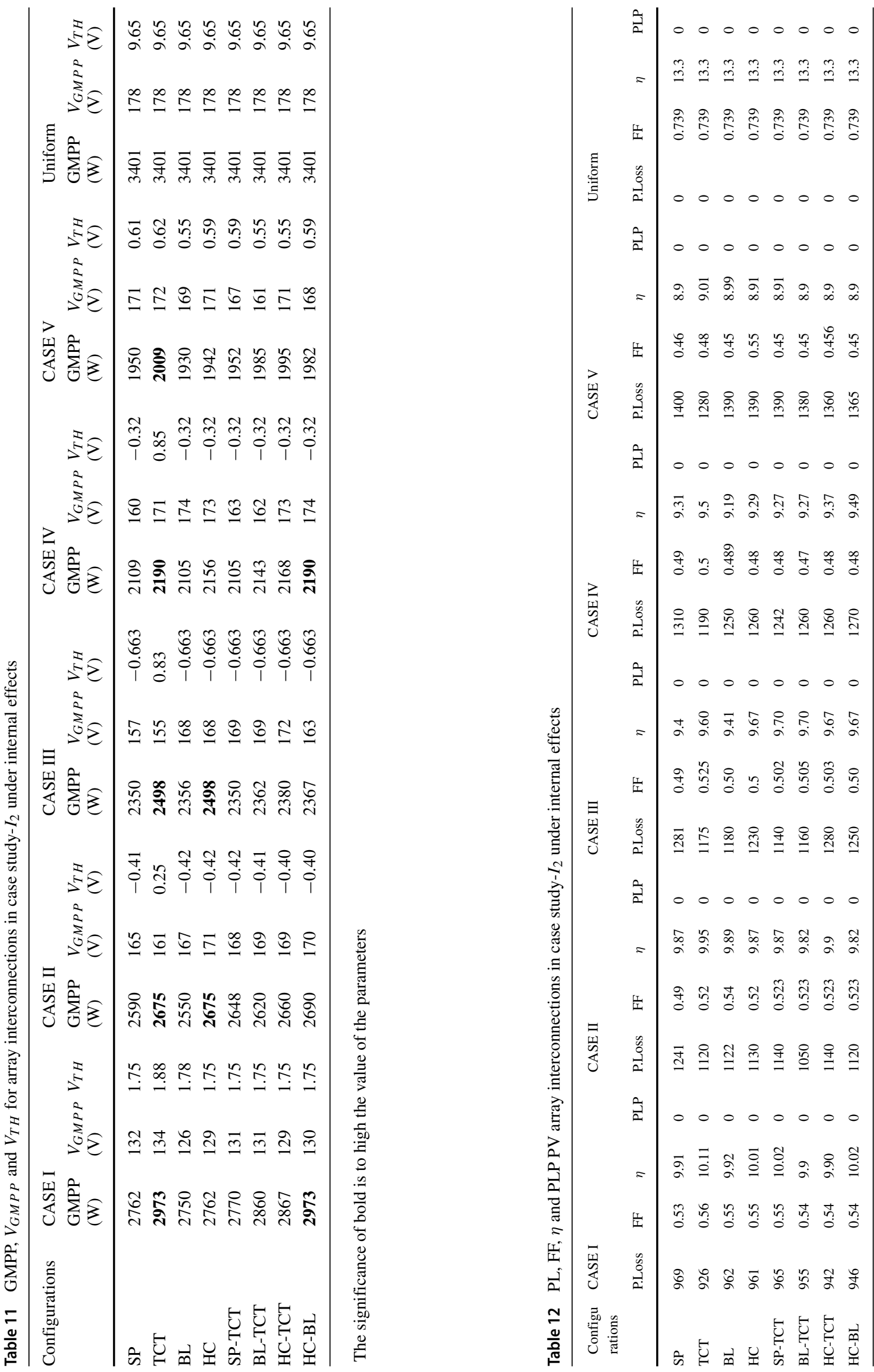


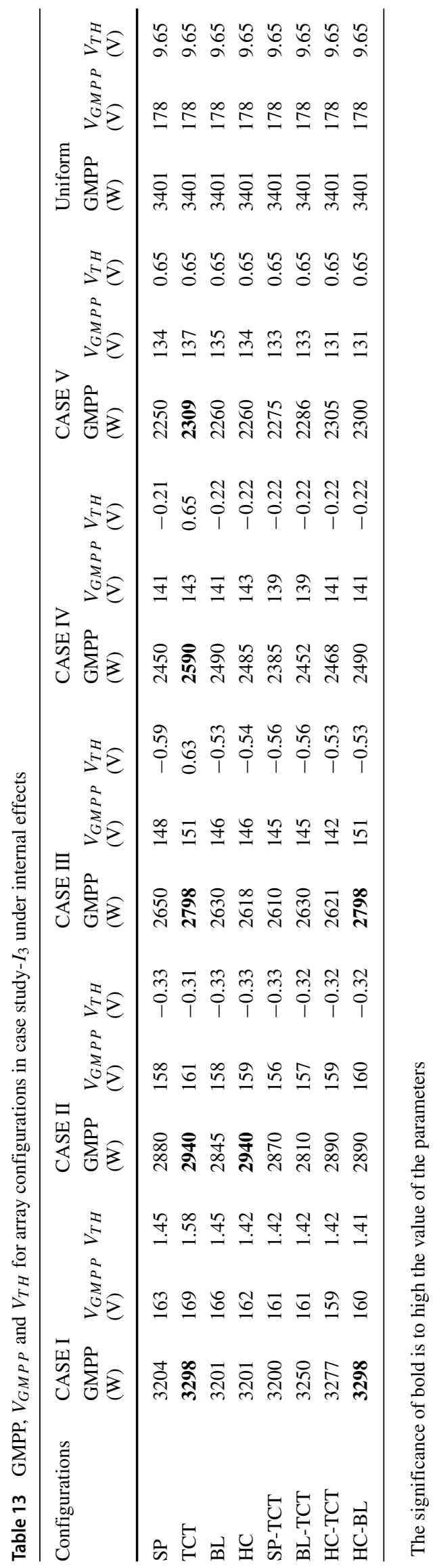

From case study- $I_{3}$, it is noted that decreasing the ideality factor of the PV modules reduced the maximum power production and voltage of the array interconnections. Under this case, the obtained parameters such as GMPP, $V_{G M P P}$ and $V_{T H}$ are presented in Table 13. Also, the other parameters such as PL, FF, $\eta$, and PLP are given in Table 14. It is found from the table that the TCT PV array is produced the highest GMPP as compared to the other interconnections in most cases.

Under all mismatch cases, the obtained parameters such as GMPP, $V_{G M P P}, V_{T H}$, PL, FF, $\eta$ and PLP of PV array connections are compared with the uniform condition (refer in Tables 3-14). In uniform condition, only one maximum power point (MPP) exist in P-V characteristics, as shown in Fig. 17(b). The figure (refer in Fig. 17b) shows that PV arrays produced equal MPP with respect to the maximum voltage of $176 \mathrm{~V}$. The other evaluated parameters in uniform conditions such as PL, FF, $\eta$, and PLP are listed in Tables 3-14.

\section{Energy Yields for PV Array Interconnections}

In the PV array, the shading effect occupies a smaller area. As a consequence, the shaded area does not allow the current flow between PV modules. The shaded module consumes the power rather than production. Under this situation, the solar PV array's power is much less than the designed one. One of the approaches to overcome this difficulty is the PV modules interconnection that allows the current flow in the PV array under PSCs. Various types of connections for the PV array are available in the literature, such as series-parallel, total-cross-tied, bridge-link, honeycomb, SP-TCT, and BL-TCT. The most challenging aspect of constructing array interconnections is selecting the size of the PV modules and cables.

In this section, a simple calculation is performed to estimate the revenue from energy savings of PV array connections for $3.4 \mathrm{~kW}$ (i.e., $5 \times 4$ array) solar plant under PSCs. The shading condition is given in Fig. 5. Each shading case can stay up to 10 minutes in 1 sun hour. The $5 \times 4$ array consists of $20 \mathrm{PV}$ modules connected in different styles, as mentioned above. Each module generates $170 \mathrm{~W}$ peak power at STC. The short circuit current $\left(I_{s c}\right)$ of each module is $5.2 \mathrm{~A}$, and hence the wire used for connecting the modules in series in each column must have an ampacity of 1.56 times $I_{s c}$ (i.e., $7.8 \mathrm{~A}$ ), as per the National Electric Code [35]. Hence, 20 AWG wires, which have an ampacity of 8.1 $\mathrm{A}$ in the enclosed condition. The various cost components of the system that have been taken into account are: PV modules $(\$ 11,480)$, wiring $(\$ 580)$, and monitoring system $(\$ 10,900)$. Table 15 shows income generation calculations for each PV array at the tariff Rs. 15 per unit cost. In addition 


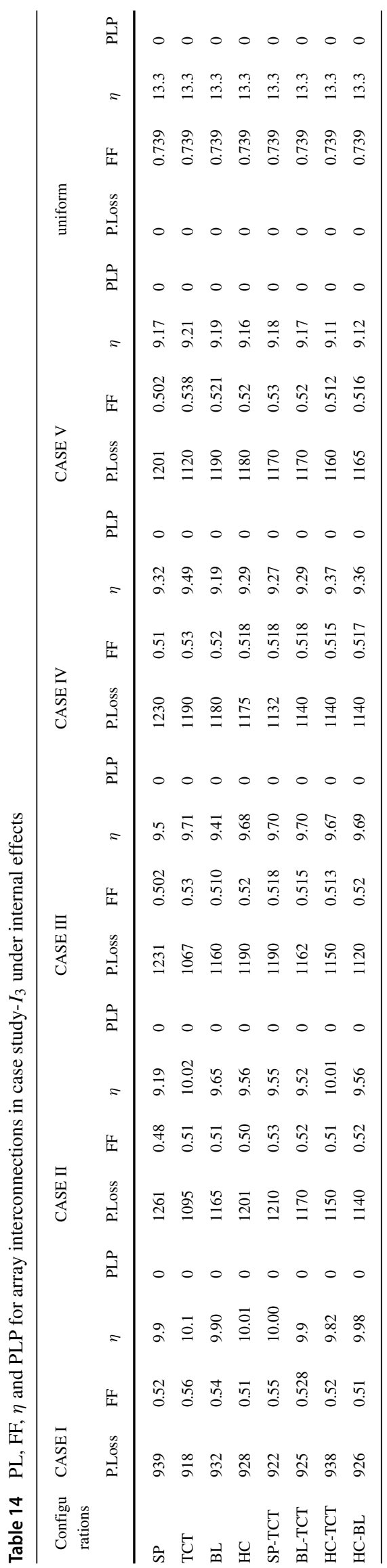

to this, the estimated parameters are graphically represented in Fig. 18.

Table 15 shows that the TCT array is generated the highest energy with improved income as compared to the other array interconnections. Also, the proposed HC-TCT and HC-BL arrays delivered more income $(\$)$ equal to the TCT and far from the other interconnections.

\section{Discussions}

This article examines the performance of eight PV array interconnections under both internal and external mismatch effects. Six case studies relating to internal and external mismatch situations are taken into account to analyse power production's impact. For the internal mismatch study, the internal parameters of the $\mathrm{PV}$ modules, such as $R_{S}, R_{P}$ and $n$, are varied. The PV modules are subjected to partially shaded in a row, column, and diagonal wise in the external investigation.

The study revealed that the variations in internal parameters (i.e., majorly $R_{S}$ ) affect the PV arrays' output power. These variations are listed in Tables 9-14. The obtained results concluded that the TCT array shows better performance compared to other interconnections. Besides, the proposed connections (HC-BL and HC-TCT) produced the highest maximum power and fill-factor, which nearer to the TCT array and far from the other array interconnections. In the external case, row shading resulted in a higher power output reduction than those for other shading conditions (refer in Tables 3-8). Compared with other interconnections, the TCT array is provided better results. Also, the proposed HC-BL and HC-TCT PV arrays performance comparable to TCT under most shading cases.

\section{Merits of Proposed Hybrid PV Array Interconnections}

Among the conventional and hybrid connections, the TCT array is exhibited superior performance under both mismatch situations. The drawback of the TCT array is that if one or more PV modules are shaded or malfunctioned in a row, the PV array's overall current decreases. Also, the TCT array installation is time-consuming and required additional wiring than $\mathrm{SP}, \mathrm{BL}$, and $\mathrm{HC}$ array interconnections. In this paper, hybrid interconnections are suggested to solve these problems. The advantage of the proposed connections is that the current can flow in the PV array with the tie-lines provided between modules, even if shading occurs. The performance of the proposed interconnections is relatively similar to the TCT array and higher than those of other conventional and hybrid interconnections under internal and external mismatch effects. The proposed 
Table 15 Obtained revenue generation from energy savings under case study- $E_{1}$

\begin{tabular}{|c|c|c|c|c|c|c|c|c|}
\hline Shadings \& Index & $\mathrm{SP}$ & TCT & BL & $\mathrm{HC}$ & SP-TCT & BL-TCT & HC-TCT & HC-BL \\
\hline case-I & $2735 \mathrm{~W}$ & $2687 \mathrm{~W}$ & $2687 \mathrm{~W}$ & $2730 \mathrm{~W}$ & $2690 \mathrm{~W}$ & $2700 \mathrm{~W}$ & $2730 \mathrm{~W}$ & $2700 \mathrm{~W}$ \\
\hline case-II & $2450 \mathrm{~W}$ & $2580 \mathrm{~W}$ & $2580 \mathrm{~W}$ & $2500 \mathrm{~W}$ & $2500 \mathrm{~W}$ & $2512 \mathrm{~W}$ & $2580 \mathrm{~W}$ & $2530 \mathrm{~W}$ \\
\hline case-III & $2470 \mathrm{~W}$ & $2508 \mathrm{~W}$ & $2485 \mathrm{~W}$ & $2500 \mathrm{~W}$ & $2500 \mathrm{~W}$ & $2500 \mathrm{~W}$ & $2508 \mathrm{~W}$ & $2508 \mathrm{~W}$ \\
\hline case-IV & $2475 \mathrm{~W}$ & $2480 \mathrm{~W}$ & $2480 \mathrm{~W}$ & $2471 \mathrm{~W}$ & $2470 \mathrm{~W}$ & $2470 \mathrm{~W}$ & $2475 \mathrm{~W}$ & $2480 \mathrm{~W}$ \\
\hline case- $\mathrm{V}$ & $2400 \mathrm{~W}$ & $2400 \mathrm{~W}$ & $2400 \mathrm{~W}$ & $2400 \mathrm{~W}$ & $2400 \mathrm{~W}$ & $2400 \mathrm{~W}$ & $2400 \mathrm{~W}$ & $2400 \mathrm{~W}$ \\
\hline Total extracted energy per day kW-h & 12.8 & 14.1 & 13.1 & 13.2 & 13.1 & 12.5 & 13.5 & 13.7 \\
\hline Total extracted energy per year kW-h & 4672 & 5146.5 & 4746.5 & 4764 & 4699.5 & 4672 & 4918.3 & 4946.5 \\
\hline Total revenue generated per year Rs. $15 / \mathrm{kW}-\mathrm{h}$ & 70080 & 77197.5 & 70980 & 71460 & 71992.5 & 69974.5 & 73992.5 & 74974.5 \\
\hline Total income in $\$$ per year & 1120.5 & 1290.2 & 1220.2 & 1220.2 & 1238.6 & 1120.5 & 1276.3 & 1280.2 \\
\hline
\end{tabular}

interconnections required less wiring for installation than the TCT. Moreover, the annual income $(\$)$ generated by the proposed connections comparable with the TCT array and far away from the other array interconnections.

Table 16 shows the power loss comparison between internal and external mismatch effects. The table shows that the external mismatch loss is quite severe than the internal loss on PV arrays. The work presented in this paper is represented in a flow chart, as shown in Fig. 19.

\section{Conclusion}

In this paper, the following studies have been reviewed

- The performance of conventional and hybrid PV array connections is analysed under mismatch effects on $5 \times 4 \mathrm{PV}$ arrays by comparing the GMPP, $V_{G M P P}$, $V_{T H}$, PL, FF, $\eta$ and PLP parameters using MATLABSIMULINK.

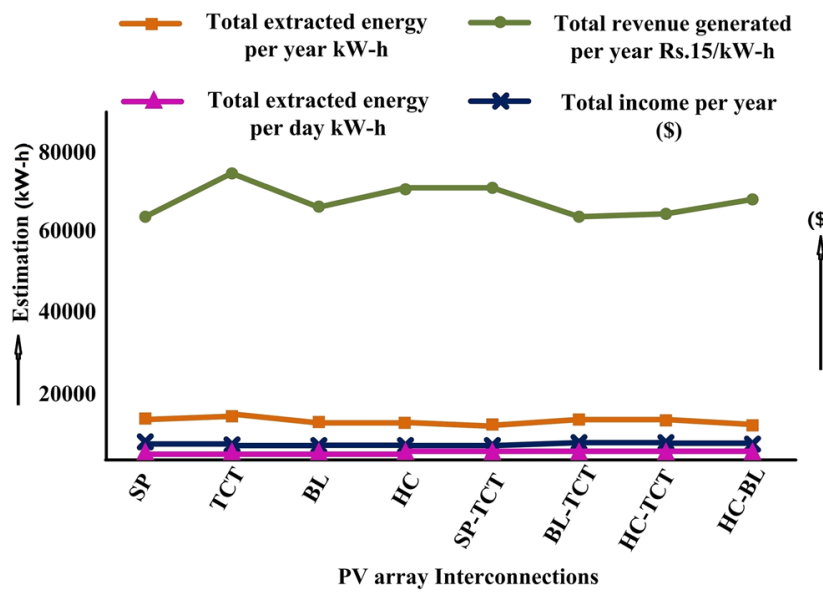

Fig. 18 Estimated energy indices for array interconnections
- Two types of mismatch studies are carried out: (i) internal mismatch and (ii) external mismatch. In internal mismatch, the TCT array is reduced the average PL by $9.5 \%$ and increased the MPP by $12 \%$, FF by $7.8 \%$ compared with those other connections in most cases in the case study- $I_{1}$. Similarly, the TCT array is reduced the average PL by $7 \%$ and increased the MPP by $10 \%$, FF by $6.8 \%$ for case study- $I_{2}$, and the TCT array is reduced the average PL by $7.6 \%$ and increased the MPP by $11 \%$, FF by $6.5 \%$ for case study- $I_{3}$.

- In external mismatch, the TCT array is reduced the average PL by $7.5 \%$ and increased the GMPP by $10 \%$, FF by $6.8 \%$ under most shading cases in the case study$E_{1}$. Similarly, the TCT array is reduced the average PL by $7 \%$ and increased the GMPP by $10.6 \%$, FF by $6.9 \%$ for case study- $E_{2}$, and the TCT array is reduced the average PL by $8.1 \%$ and increased the GMPP by $12.2 \%$, FF by $7.8 \%$ for case study- $E_{3}$.

- The two main observations are made from this study are as follows: (i) TCT PV array is enhanced the overall performance under both internal and external

Table 16 Calculated power loss under internal and external mismatch effects

\begin{tabular}{lll}
\hline PV arrays & $\begin{array}{c}\text { Average power loss }(\%) \\
\text { Internal mismatch effects }\end{array}$ & External mismatch effects \\
\hline SP & $19.2 \%$ & $22.2 \%$ \\
TCT & $16.8 \%$ & $17.2 \%$ \\
BL & $18.1 \%$ & $21.9 \%$ \\
HC & $18.6 \%$ & $21.7 \%$ \\
SP-TCT & $17.9 \%$ & $22.1 \%$ \\
BL-TCT & $18.8 \%$ & $21.5 \%$ \\
HC-TCT & $17.1 \%$ & $18.8 \%$ \\
HC-BL & $16.2 \%$ & $18.1 \%$ \\
\hline
\end{tabular}




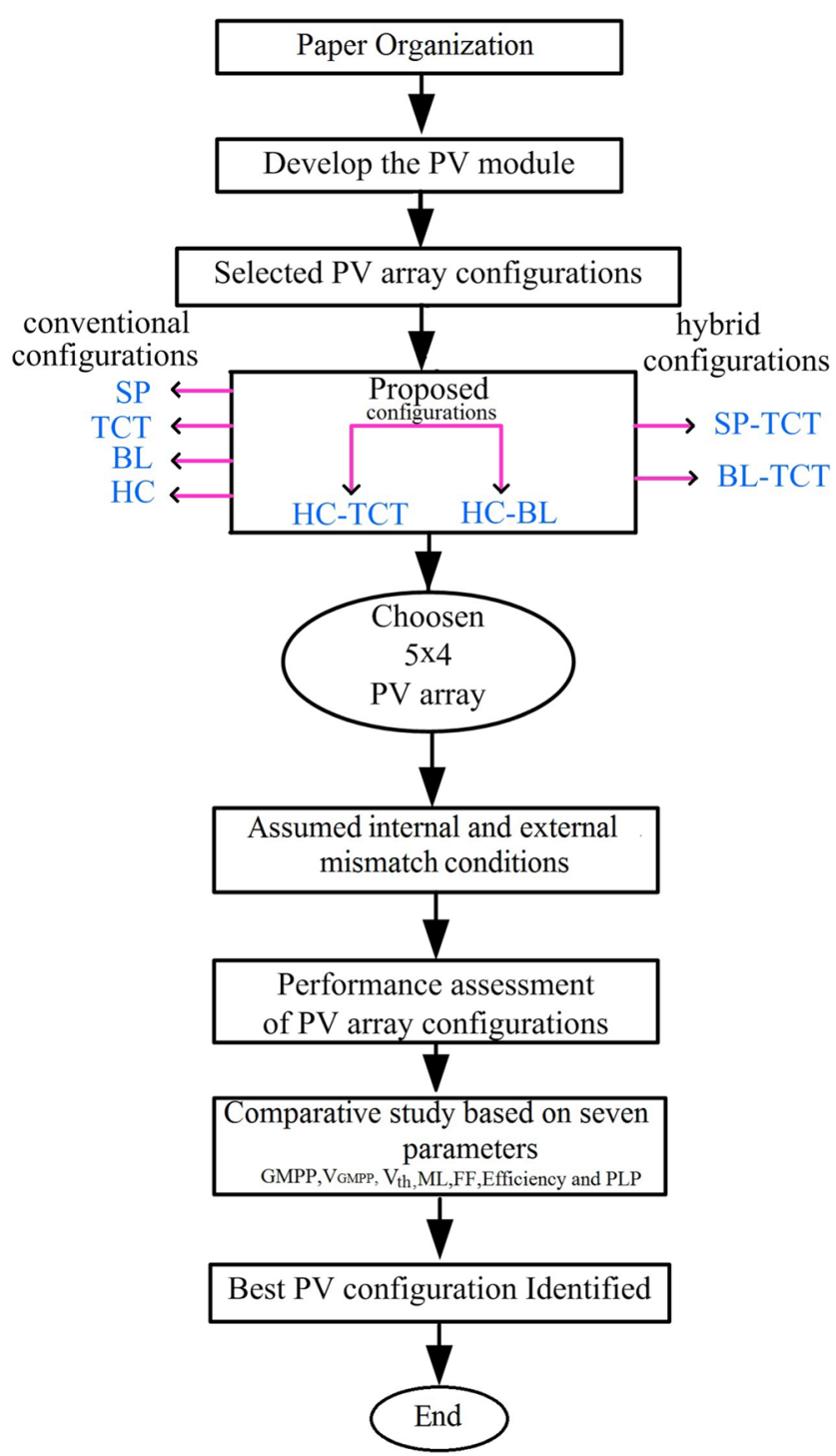

Fig. 19 Flowchart of this study

mismatch effects. (ii) The proposed HC-TCT and HCBL PV arrays also showed superior performance in both mismatch effects.

\section{Financial and Ethical disclosures}

Funding There is no funding for this paper.

\section{Declarations}

Conflict of Interest On behalf of all authors, the corresponding author states that there is no conflict of interest.

\section{References}

1. Samal S, Hota PK, Barik PK (2020) Performance improvement of a distributed generation system using unified power quality conditioner. Technol Econ Smart Grids Sustain Energy 5(1):1-16
2. Garniwa I, Herdiansyah $\mathrm{H}$ et al (2021) Sustainability index of solar power plants in remote areas in indonesia. Technol Econ Smart Grids Sustain Energy 6(1):1-14

3. Sai Krishna G, Moger T (2019) Improved sudoku reconfiguration technique for total-cross-tied pv array to enhance maximum power under partial shading conditions. Renew Sust Energ Rev 109:333348

4. Sai Krishna G, Moger T (2019) Reconfiguration strategies for reducing partial shading effects in photovoltaic arrays State of the art. Sol Energy 182:429-452

5. Kaushika ND, Rai AK (2007) An investigation of mismatch losses in solar photovoltaic cell networks. Energy 32(5):755-759

6. Belhachat $F$, Larbes C (2018) A review of global maximum power point tracking techniques of photovoltaic system under partial shading conditions. Renew Sust Energ Rev 92:513-553

7. Malathy S, Ramaprabha R (2017) Reconfiguration strategies to extract maximum power from photovoltaic array under partially shaded conditions. Renewable and Sustainable Energy Reviews

8. Bingol O, Ozkaya B (2018) Analysis and comparison of different pv array configurations under partial shading conditions. Sol Energy 160:336-343

9. Wang Y-J, Hsu P-C (2011) An investigation on partial shading of pv modules with different connection configurations of pv cells. Energy 36(5):3069-3078

10. Gautam NK, Kaushika ND (2002) Reliability evaluation of solar photovoltaic arrays. Sol Energy 72(2):129-141

11. Gautam NK, Kaushika ND (2001) Network analysis of faulttolerant solar photovoltaic arrays. Sol Energy Mater Sol Cells 69(1):25-42

12. Kaushika ND, Gautam NK (2003) Energy yield simulations of interconnected solar pv arrays. IEEE Trans Energy Convers 18(1):127-134

13. Belhachat F, Larbes C (2015) Modeling, analysis and comparison of solar photovoltaic array configurations under partial shading conditions. Sol Energy 120:399-418

14. Shams El-Dein MZ, Kazerani M, Salama MMA (2013) An optimal total cross tied interconnection for reducing mismatch losses in photovoltaic arrays. IEEE Trans Sustain Energy 4(1):99107

15. Shams El-Dein MZ, Kazerani M, Salama MMA (2013) Optimal photovoltaic array reconfiguration to reduce partial shading losses. IEEE Trans Sustain Energy 4(1):145-153

16. Indu Rani B, Saravana Ilango G, Nagamani C (2013) Enhanced power generation from pv array under partial shading conditions by shade dispersion using su do ku configuration. IEEE Trans Sustain Energy 4(3):594-601

17. Ramaprabha R, Mathur BL (2012) A comprehensive review and analysis of solar photovoltaic array configurations under partial shaded conditions. International Journal of Photoenergy

18. Dhimish M, Holmes V, Mehrdadi B, Dales M, Chong B, Li Z (2017) Seven indicators variations for multiple pv array configurations under partial shading and faulty pv conditions. Renew Energy 113:438-460

19. Pendem SR, Mikkili S (2018) Modelling and performance assessment of pv array topologies under partial shading conditions to mitigate the mismatching power losses. Sol Energy 160:303-321

20. Pendem SR, Mikkili S (2018) Modeling, simulation and performance analysis of solar pv array configurations (series, series-parallel and honey-comb) to extract maximum power under partial shading conditions. Energy Rep 4:274-287

21. Yadav AS, Pachauri RK, Chauhan YK (2016) Comprehensive investigation of pv arrays with puzzle shade dispersion for improved performance. Sol Energy 129:256-285

22. Ahmad R, Murtaza AF, Sher HA, Shami UT, Olalekan S (2017) An analytical approach to study partial shading effects on pv array supported by literature. Renew Sust Energ Rev 74:721-732 
23. Nguyen D, Lehman B (2008) A reconfigurable solar photovoltaic array under shadow conditions, pp 980-986

24. Picault D, Raison B, Bacha S, Aguilera J, de la Dasa J (2010) Changing photovoltaic array interconnections to reduce mismatch losses: a case study, pp 37-40

25. Bidram A, Davoudi A, Balog RS (2012) Control and circuit techniques to mitigate partial shading effects in photovoltaic arrays. IEEE J Photovolt 2(4):532-546

26. Bana S, Saini RP (2017) Experimental investigation on power output of different photovoltaic array configurations under uniform and partial shading scenarios. Energy 127:438-453

27. Pendem SR, Mikkili S (2018) Modeling, simulation, and performance analysis of pv array configurations (series, seriesparallel, bridge-linked, and honey-comb) to harvest maximum power under various partial shading conditions. Int J Green Energy 15(13):795-812

28. Satpathy PR, Jena S, Sharma R (2018) Power enhancement from partially shaded modules of solar pv arrays through various interconnections among modules. Energy 144:839-850

29. Jha V, Triar US (2019) A detailed comparative analysis of different photovoltaic array configurations under partial shading conditions. Int Trans Electr Energy Syst:e12020

30. Wang Y-J, Hsu P-C (2010) Analytical modelling of partial shading and different orientation of photovoltaic modules. IET Renew Power Gener 4(3):272-282

31. Gao L, Dougal RA, Liu S, Iotova AP (2009) Parallel-connected solar pv system to address partial and rapidly fluctuating shadow conditions. IEEE Trans Ind Electron 56(5):1548-1556

32. Roopa P, Edward Rajan S, Pon Vengatesh R (2011) Performance analysis of pv module connected in various configurations under uniform and non-uniform solar radiation conditions. In: 2011 International conference on Recent advancements in electrical, electronics and control engineering (ICONRAEeCE). IEEE, pp 142-149

33. Pon Vengatesh R, Edward Rajan S (2016) Analysis of pv module connected in different configurations under uniform and nonuniform solar radiations. Int J Green Energy 13(14):1507-1516

34. Perveen G, Rizwan M, Goel N (2018) Intelligent model for solar energy forecasting and its implementation for solar photovoltaic applications. J Renew Sustain Energy 10(6):063702

35. Potnuru SR, Pattabiraman D, Ganesan SI, Chilakapati N (2015) Positioning of pv panels for reduction in line losses and mismatch losses in pv array. Renew Energy 78:264-275

Publisher's Note Springer Nature remains neutral with regard to jurisdictional claims in published maps and institutional affiliations. 